Review Article

\title{
Aging: Molecular Pathways and Implications on the Cardiovascular System
}

\author{
Arthur José Pontes Oliveira de Almeida, Thaís Porto Ribeiro, and Isac Almeida de Medeiros
}

Departamento de Ciências Farmacêuticas/Centro de Ciências da Saúde, Universidade Federal da Paraíba, Cidade Universitária-Campus I, Caixa Postal 5009, 58.051-970 João Pessoa, PB, Brazil

Correspondence should be addressed to Isac Almeida de Medeiros; isac@ltf.ufpb.br

Received 5 May 2017; Accepted 27 June 2017; Published 9 August 2017

Academic Editor: Consuelo Borrás

Copyright (c) 2017 Arthur José Pontes Oliveira de Almeida et al. This is an open access article distributed under the Creative Commons Attribution License, which permits unrestricted use, distribution, and reproduction in any medium, provided the original work is properly cited.

\begin{abstract}
The world's population over 60 years is growing rapidly, reaching $22 \%$ of the global population in the next decades. Despite the increase in global longevity, individual healthspan needs to follow this growth. Several diseases have their prevalence increased by age, such as cardiovascular diseases, the leading cause of morbidity and mortality worldwide. Understanding the aging biology mechanisms is fundamental to the pursuit of cardiovascular health. In this way, aging is characterized by a gradual decline in physiological functions, involving the increased number in senescent cells into the body. Several pathways lead to senescence, including oxidative stress and persistent inflammation, as well as energy failure such as mitochondrial dysfunction and deregulated autophagy, being ROS, AMPK, SIRTs, mTOR, IGF-1, and p53 key regulators of the metabolic control, connecting aging to the pathways which drive towards diseases. In addition, senescence can be induced by cellular replication, which resulted from telomere shortening. Taken together, it is possible to draw a common pathway unifying aging to cardiovascular diseases, and the central point of this process, senescence, can be the target for new therapies, which may result in the healthspan matching the lifespan.
\end{abstract}

\section{Introduction}

According to the United Nations, the worldwide population over 60 years will grow exponentially over the next decades, rising from $12 \%$ in 2015 to $22 \%$ in 2050 (Figure 1(a)) [1]. Despite the increase of lifespan, individuals do not necessarily present an improvement in their quality of life (Figure 1(b)). Diseases such as cancer, diabetes, and neurodegenerative and cardiovascular diseases (CVDs) have their prevalence increased with age, being known as age-related diseases. In 2012 , $68 \%$ of deaths were associated with these diseases, highlighting to CVDs, corresponding to $46 \%$ of this total [2].

Aging is a universal and multifactorial process characterized by a gradual decline of physiological functions, occurring at the molecular, cellular, and tissue levels [3], which involve a series of mechanisms such as deregulated autophagy, mitochondrial dysfunction, telomere shortening, oxidative stress, systemic inflammation, and metabolism dysfunction $[4,5]$.
The deregulation of these pathways leads the cell to a senescent state, which contributes to aging phenotype and, eventually, driving towards age-related diseases (Figure 1(c)). Although many theories have been proposed to explain the aging process, neither of them appears to be fully satisfactory.

Therefore, this review draws an integrated approach to aging, addressing the mechanisms that lead the cell to senescence and how this process can contribute to aging and agerelated diseases, with emphasis on the cardiovascular system.

\section{Senescence: Cellular Retirement}

Senescence is the cellular state characterized by cell cycle arrest, usually in G1 phase, but the cells remain metabolically active [6]. Senescent cells secrete a variety of proinflammatory cytokines, interleukins, and growth factors, which has 


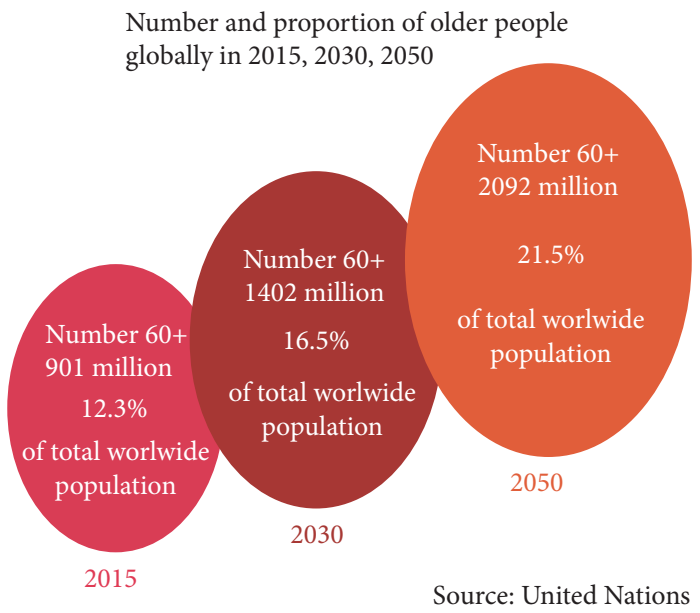

(a)

Age-related diseases raise exponentially: This is not a coincedence!

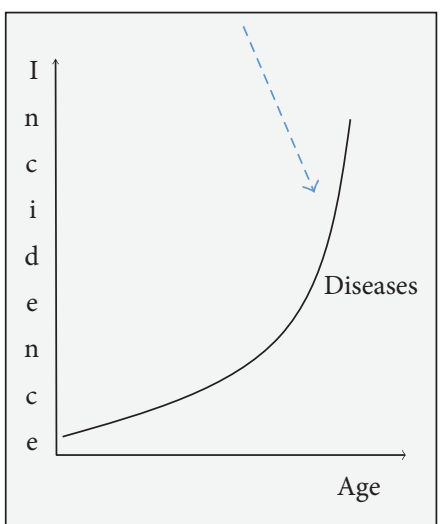

Prolonging the healthy years of life: Improving lifespan and healthspan!

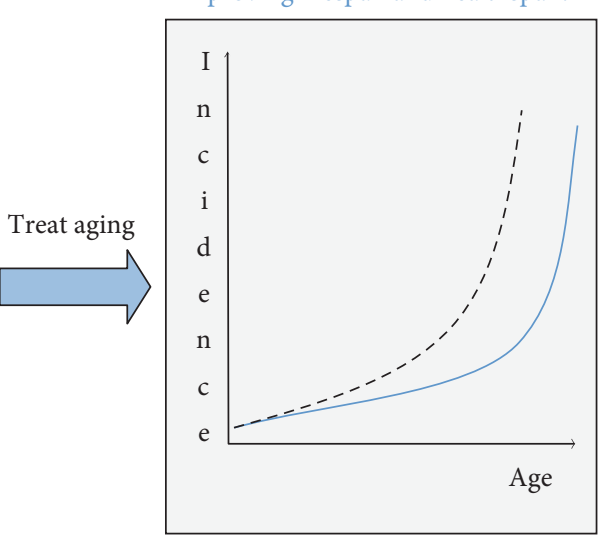

(b)

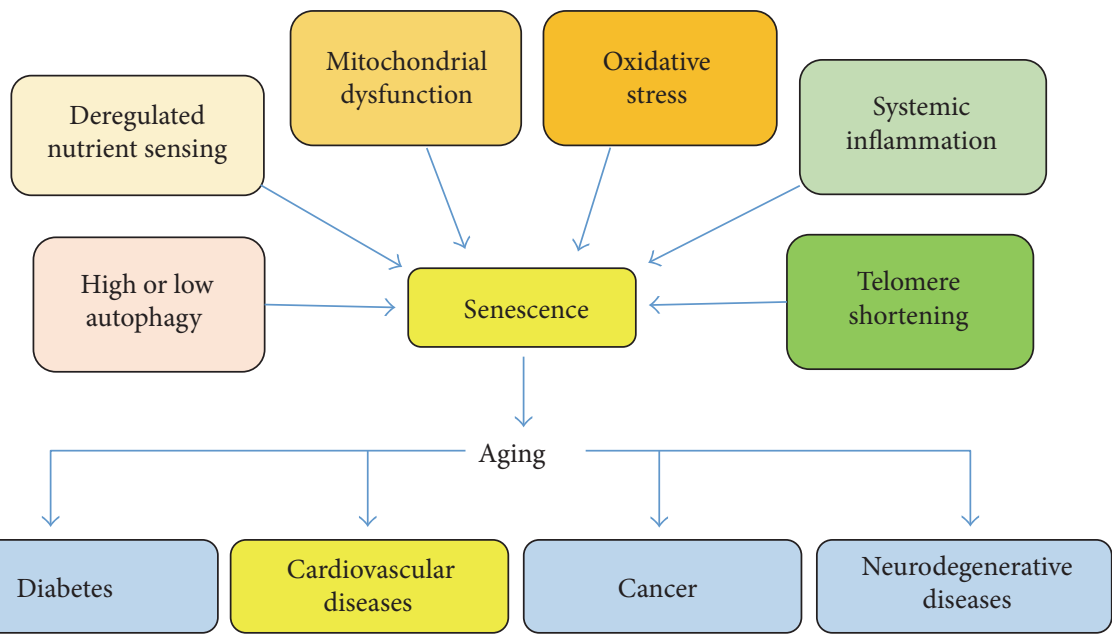

(c)

FIGURE 1: Aging and health. (a) The global population will increase from $12 \%$ in 2015 to almost $22 \%$ in 2050 [1]. (b) Despite the increase in lifespan, the individual healthspan does not follow this growth, which means that targeting aging with new therapies is essential to minimize the onset of aging-related diseases. (c) At the cellular level, aging is characterized by an increase of senescent cells in the organism, caused by several factors, including oxidative stress, systemic inflammation, mitochondrial dysfunction, deregulated nutrient sensitivity, autophagy dysfunction, and telomere shortening. The same mechanisms that lead to aging drive towards age-related diseases, in particular, the cardiovascular diseases, the major cause of death in the worldwide. 


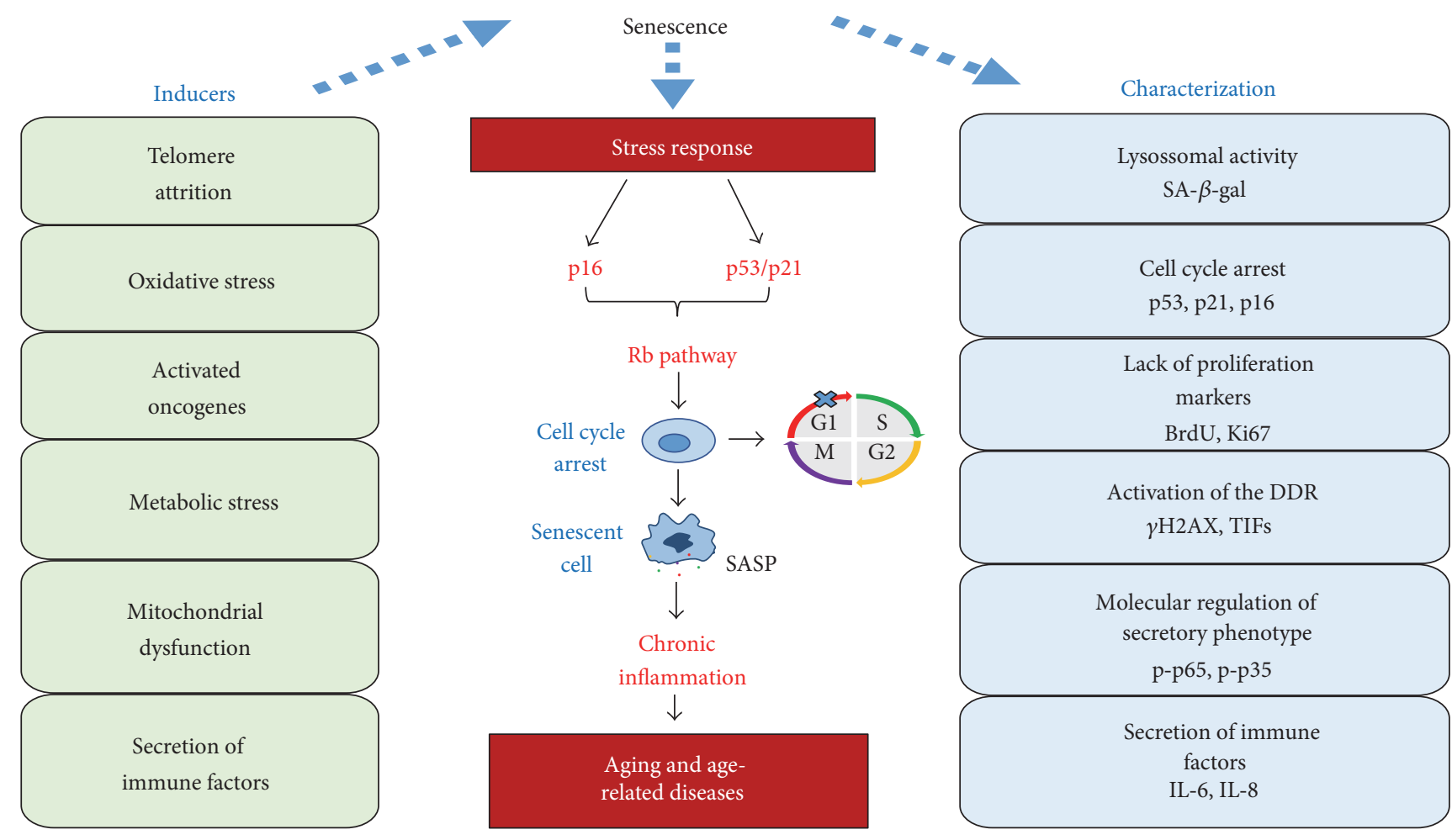

FIGURE 2: Senescence and aging. Aging is characterized by senescent cell accumulation into the body. Senescence can be achieved replicatively or induced by stress. Once activated, the p16 and p53/p21 pathways converge with each other, regulating the Rb mechanism, leading to cell cycle arrest, and consequently, the senescence. This results in the release of cytokines and chemokines, driving towards a systemic inflammatory condition that lead to aging and age-related diseases. The senescent cells are characterized by a high lysosomal $\beta$ galactosidase activity and, in association with others characteristic factors, consist the gold standard for the senescence characterization.

been reported as "secretory phenotype associated with senescence" (SASP) [7].

Senescent cells are usually removed by the immune system; however, in consequence of immunosenescence, they start to accumulate with age $[8,9]$. It is believed that increases in proinflammatory mediators are initially a mechanism of "cleaning" the senescent cells, but with immunosenescence, the stimulus generated by the senescent cells are not able to recruit enough functional cells of the immune system, a long-term process that play a negative effect on aging and age-related diseases $[10,11]$. Furthermore, there is a limit made by senescence in stem cell lineages, "stem cell exhaustion," resulting in a decreased regenerative potential [12, 13]. These two hallmarks, accumulation of senescent cells and loss in function of regenerative lineages, contribute to aging simultaneously.

Two major pathways control the senescent state: p53/p21 and $\mathrm{p} 16 / \mathrm{pRB}$. Both pathways are complex and have several regulators; however, in the cardiovascular system, they are still not totally clarified $[3,14,15]$. In response to DNAdamage response (DDR), p53 is stimulated and induces p21 expression, a cyclin-dependent kinase (CDK) inhibitor. In consequence of CDK activity suppression, the retinoblastoma protein $(\mathrm{pRB})$ is activated. The p16, another CDK inhibitor, also prevents the $\mathrm{pRB}$ phosphorylation, leading to $\mathrm{pRB}$ inactivation $[6,15,16]$. Thereby, $\mathrm{pRB}$ plays a central role in the senescence and its activity is mainly attributed to its ability to bind and inactivate the E2F family of transcription factors, which induces cell cycle proteins and DNA replication factors required for cell growth [16]. In this way, there is a reciprocal regulation between the p53/p21 and p16/pRB signalling; however, these pathways can induce senescence independently [6]. Indeed, "cleaning" naturally occurring p16 positive cells improves healthspan, which presents several benefits on the cardiovascular system [17].

Morphologically, the senescent cells are characterized by the increase in volume, and if adherent, they adopt a flattened morphology; however, there is no marker exclusive to a senescent state [3]. The first marker to be used was the detection of senescence associated with $\beta$-galactosidase (SA- $\beta$-gal) activity [18], which actually indicates increased lysosomal activity of $\beta$-galactosidase [19]. Recently, several molecular markers were developed and their association with SA- $\beta$ gal is the gold standard to confirm the senescent stage in vascular cells [20]. Such markers represent the cell cycle arrest (p16, p21, and p53), lack of proliferation markers (Ki67, BrdU), expression of secretion factors (IL-6, IL-8), activation of secretory phenotype-regulating pathways ( $\mathrm{p}$-p65 or $\mathrm{p}$ p38), changes in chromatin (HP1, Hira), and activation of the DDR ( $\gamma \mathrm{H} 2 \mathrm{AX}, \mathrm{TIFs})$ (Figure 2) [21, 22].

Several factors lead to senescence, and one of them is the cellular division, with telomere shortening, called replicative senescence $[23,24]$. In endothelial and smooth muscle cells, senescence can also be induced by stress, such as oxidative stress and inflammation leading to DNA damage, activation of oncogenes, and changes in chromatin [14, 21]. Another 

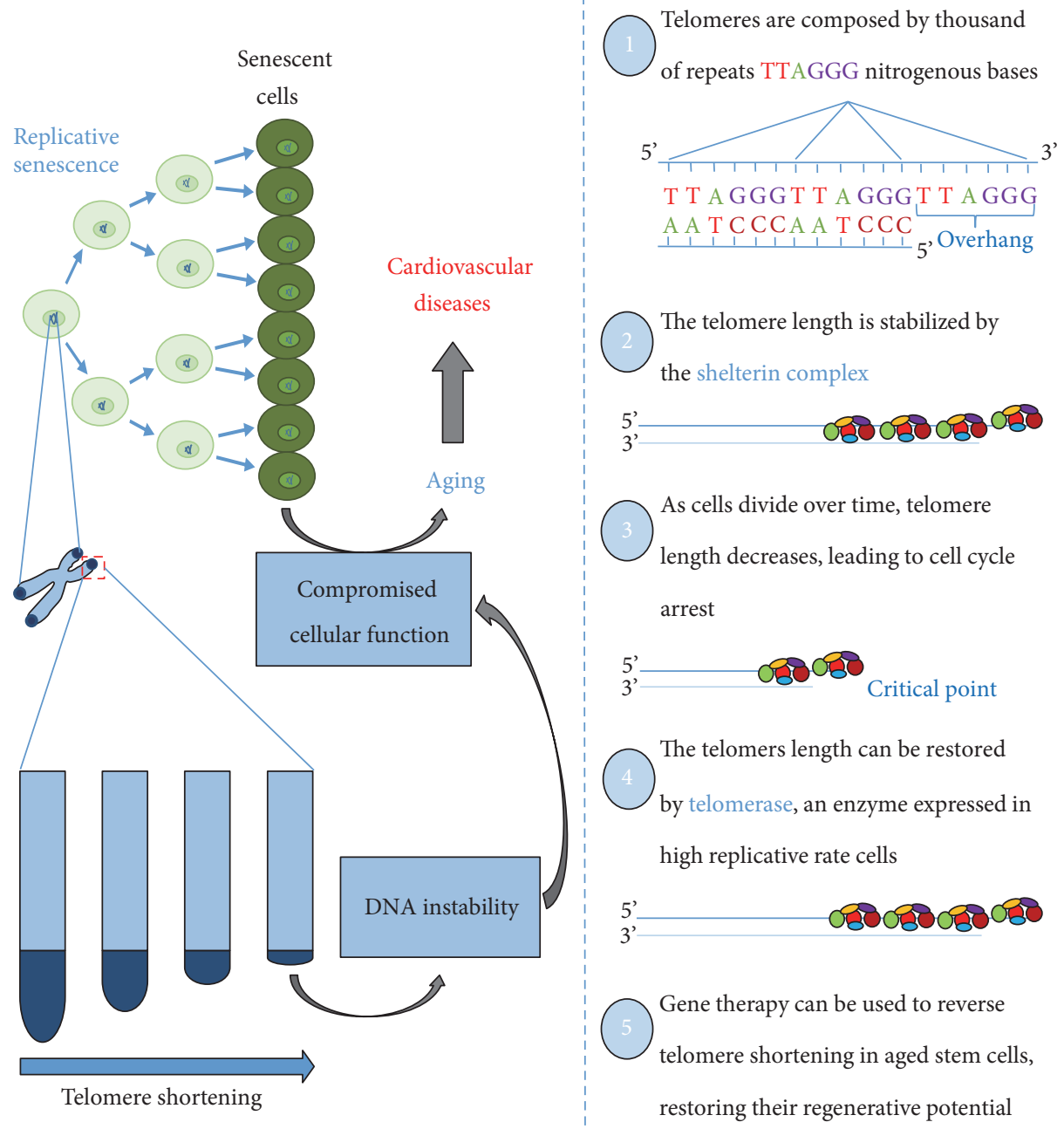

FIGURE 3: Role and function of telomeres in DNA protection. After each cell division, each chromosome loses a part of its telomeres, a region characterized by thousands of repeated sequences of nitrogenous bases. At a critical point, cells with shortened telomeres stop to divide, leading to senescence and resulting in aging and CVDs. Cells with high replicative rates such as stem cell lineages express telomerase, an enzyme capable of reversing telomere shortening. This enzyme plays a key role in the development of new therapies that aim to slow or reverse the aging process.

route that leads to senescence is the mitochondrial dysfunction, a process that decreases cellular energy supply, leading the cell to decrease its metabolic activity $[25,26]$. In addition, deficiency in the pathways of autophagy also leads the cell to the senescence through the accumulation of cellular "waste," which is toxic to the cell, including vascular cells [27].

The raising in the number of cardiac, muscular, endothelial, and endothelial progenitor senescent cells has been associated with cardiovascular dysfunction, leading to the progress of several diseases, such as hypertension, atherosclerosis, heart failure, and stroke. Therefore, therapies aimed at reversing or delaying the senescence process have been proposed for the treatment of these diseases [17, 28-31].

\section{Telomeres: The Biological Clock}

One of the hallmarks of molecular aging is the telomere shortening with the advent of age [4]. Telomeres, known as the biological clock, comprise thousands of nucleotide sequences at the end of each chromosome. In the $3^{\prime}$ side, the sequence corresponds to TTAGGG (9-15 kb, in humans) [32]. In somatic cells, after each cell division, part of these bases is lost in the process, promoting telomere shortening [23]. Thus, it is estimated a finite number of cellular divisions and, after that, cells become senescent (Figure 3) [33].

Associated with telomeres, there is a shelterin complex formed by proteins and transcription factors. This complex comprises a set of six subunits with distinct functions, which has essential participation for chromosome protection [34]. They are telomere repeat-binding factor 1 (TRF1), telomere repeat-binding factor 2 (TRF2), repressor-activator protein 1 (RAP1), TRF1- and TRF2-interacting nuclear protein 2 (TIN2), tripeptidyl-peptidase 1 (TPP1), and protection of telomere 1 (POT1) [35]. TRF1 and TRF2 bind directly to the double-stranded telomeric repeats, while POT1 recognizes the telomeric strand in the $3^{\prime}$ branch. TIN2 binds to 
TRF1 and TRF2. TIN2 also recruit the TPP1-POT1 heterodimer, reducing different shelterins to organize the final portion of the telomeres. RAP1 is recruited to the telomeres by TRF2. In addition, RAP1 can also bind along chromosomal arms regulating gene transcription [36].

The telomeres participate in the maintenance of the genome and promote stability in the replication process, avoiding undesirable recombination and chromosomal fusion $[37,38]$. When the critical telomere size is reached, the proteins cannot be recruited to maintain the T-loop nucleotide sequences. Then, the DNA repair system activates cellular checkpoints $[39,40]$. Two checkpoints have already been identified that limit cell life in response to telomeres dysfunction: the first checkpoint (M1, the first stage of mortality) is characterized by a complete cell cycle arrest, known as senescence, and it is dependent on p53 activation [32]. Cells mutated in the p53 gene may continue to divide even when the critical size of the telomeres was reached $[34,41]$. If the cell continues to divide and, consequently, the telomeres continue to decrease in size, a new checkpoint is activated (M2, the second stage of mortality), called the crisis. This point is independent of p53 and is characterized by massive chromosomal instability and cell death [42].

In some cellular lineages, such as stem cells, telomere shortening can be restored by the enzyme telomerase reverse transcriptase (TERT), together with its RNA component (TERC) [43]. Both are regulated by the shelterin complex [44]. The ability of embryogenic or induced pluripotent stem cells (iPSC) to replicate indefinitely is due to a high expression of functional TERT and TERC in these cell populations $[45,46]$. Several studies have reported that inducing TERT activity in somatic cells reverses several characteristics of aging, such as senescence $[47,48]$, which leads to cardioprotection [49]. In addition, hearts expressing TERT showed attenuated cardiac dilation, improved ventricular function, and smaller infarct scars concomitant with increased mouse survival by $17 \%$ compared with controls [50].

Furthermore, telomere shortening in circulating lymphocytes, used as an indirect marker of circulating progenitor cells, has been identified as an early-onset alarm for CVDs [51].

Cardiac telomerase activity is detectable at the earliest stages of life and is downregulated in an adult rat myocardium $[52,53]$. Recently, Richardson and colleagues showed a natural expression of telomerase functionally important in adult mammalian hearts [54], which could be targeted for cardiovascular regeneration.

Therefore, there is a great evidence that combating telomere shortening has beneficial effects on the cardiovascular system, through slowing or even reversing cellular senescence $[50,55,56]$.

\section{The Role of ROS and Oxidative Stress: A Necessary Evil}

According to the free radical theory of aging proposed by Harman in 1956, ROS leads to oxidative damage in cellular biomolecules, contributing to the decline of physiological function with aging [57]. Although a series of reviews and evidences reports the deleterious effects of ROS in aging $[58,59]$, recent studies on long-lived models and genetically altered animals challenge the role of ROS in aging [60]. In this way, ROS seems to have a double effect, initially, as an activator of a homeostatic compensatory response that increases with age in order to maintain survival through activation of various defence mechanisms plus stimulating cellular proliferation and, from a certain limit, as a factor that, instead of alleviating, aggravates the damages associated with aging (Figure 4(a)) [61, 62].

There are several sources of ROS in mammals, including mitochondrial respiration, cyclooxygenase and lipoxygenase, cytochrome p450s, xanthine oxidase, NADPH oxidase, NO synthase, peroxidase, endoplasmic reticulum, and other hemoproteins [63, 64]. Many ROS species have unpaired electrons, called free radicals. In this group, these include superoxide anion $\left(\mathrm{O}_{2}^{-} \bullet\right)$, hydroxyl radical $(\mathrm{HO} \bullet)$, nitric oxide $(\mathrm{NO} \bullet)$, and lipid radicals. Other reactive oxygen species such as hydrogen peroxide $\left(\mathrm{H}_{2} \mathrm{O}_{2}\right)$, peroxynitrite $\left(\mathrm{ONOO}^{-}\right)$, and hypochlorous acid $(\mathrm{HOCl})$ are not free radicals but have oxidizing effects that contribute to oxidative stress $[65,66]$.

The basal balance in ROS levels is mediated by the activity of a set of enzymatic and nonenzymatic complexes with the function of cellular detoxification, collectively called antioxidants [67]. Nuclear factor erythroid 2-related factor 2 (Nrf-2), a transcription factor, is the major regulator of the antioxidant enzymatic system in the vasculature, including transcription of antioxidant enzymes and phase II detoxifiers such as superoxide dismutase (SOD), catalase (CAT), glutathione peroxidase (GPx), glutathione reductase (GR), hemeoxygenase-1 (HO-1), and $\mathrm{NAD}(\mathrm{P}) \mathrm{H}$ quinone oxidoreductase-1 (NQO1). Taken together, this system is the major defence system that counteract ROS production in vivo $[68,69]$.

An imbalance to the prooxidant side leads to the physiological status known as oxidative stress, which has been linked to impaired vascular function [70].

NADPH oxidase (Nox) is an important source of ROS on the cardiovascular system [71]. There are seven Nox isoforms: Nox1, Nox2, Nox3, Nox4, Nox5, Duox1, and Duox2. All Nox are transmembrane proteins that have a catalytic site (Nox) and a regulatory protein complex [72]. Isoforms 1, 2, 4 , and 5 are expressed in various tissues including the heart and vessels. Nox 2 and Nox 4 are superexpressed in the vascular tissue of old mice [73]. The prototype of the group is the Nox 2 which is composed of 6 subunits: p47phox, p67phox, $\mathrm{p} 40$ phox, and Racl/2 which are cytosolic regulatory proteins; p22phox which is a membrane regulatory protein; and gp91phox which is a catalytic subunit present in the membrane [74].

The Nox complex is upregulated by TNF- $\alpha$ [75] and also by the activation of AT1 receptor by angiotensin II [76]. Thus, in the increase in ROS production, Nrf-2 begins to have its activity inhibited by the crosstalk with $\mathrm{Nf}-\mathrm{kB}$, which is responsible for increasing TNF- $\alpha$ levels, generating a vicious cycle [77]. As ROS are produced, TNF- $\alpha$ release increases, aggravating oxidative stress. This shift in the expression of $\mathrm{Nrf}-2$ to $\mathrm{Nf}-\mathrm{kB}$ seems to be gradual, 


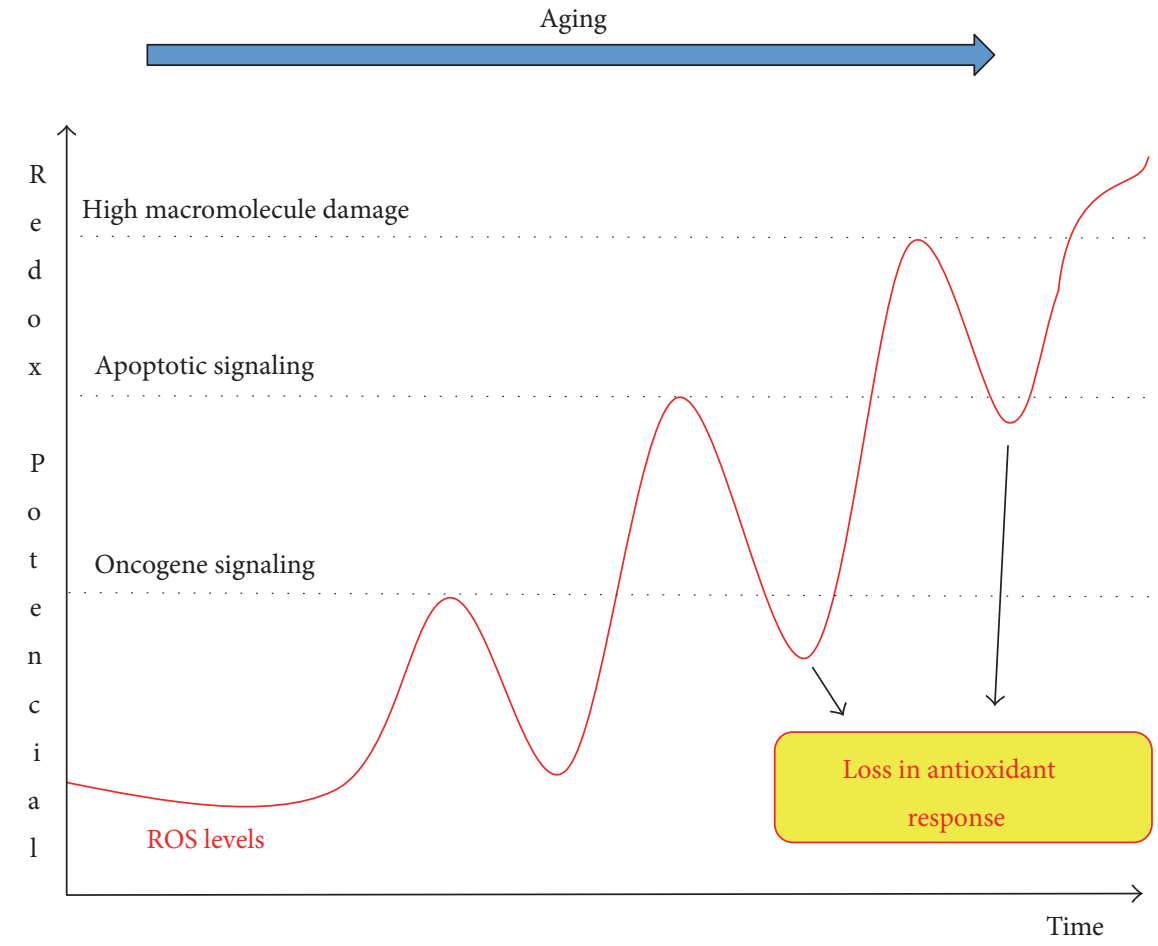

(a)

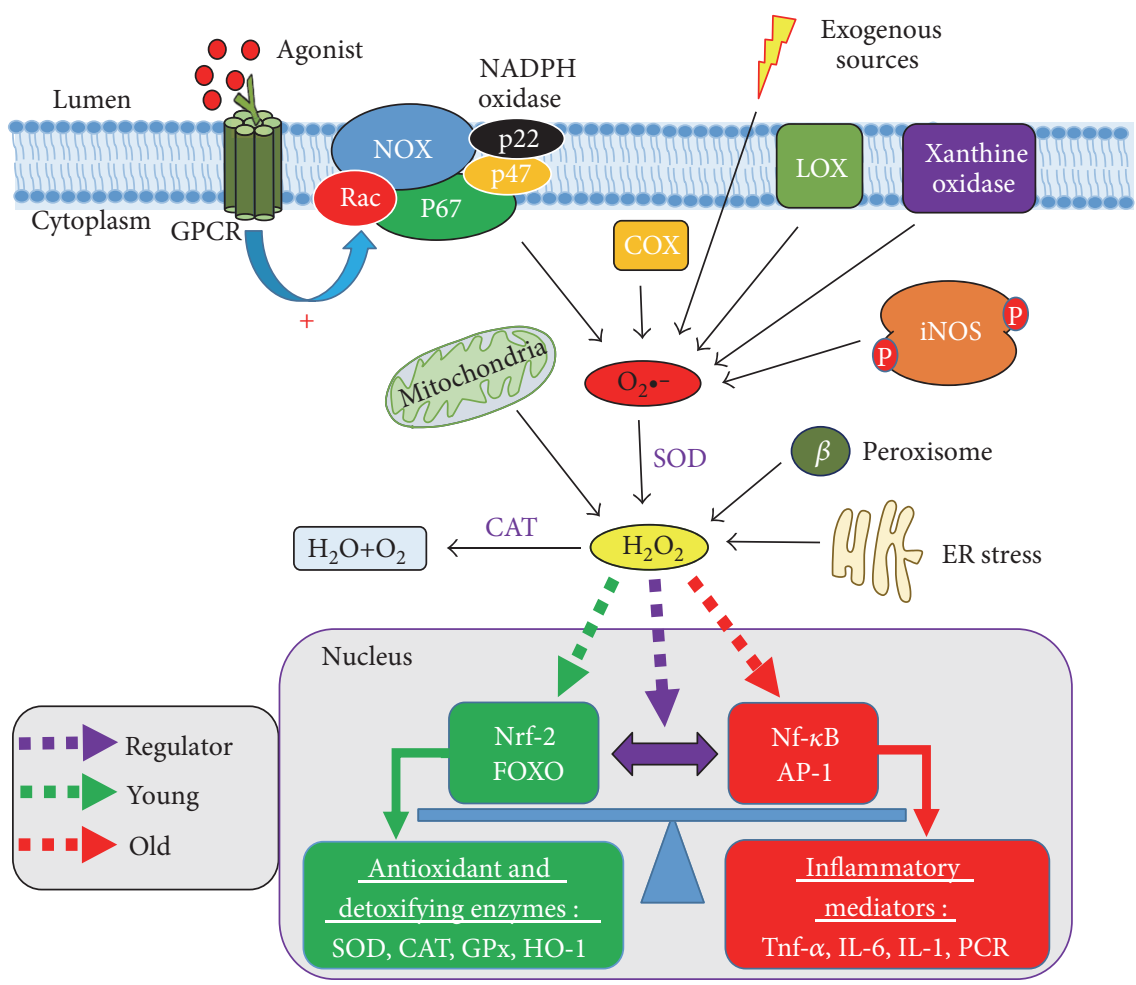

(b)

FIGURE 4: Redox potential controls cell fate. One of the hallmarks of aging is the increase in ROS levels production. New approaches define this increase as a compensatory cellular response with the original purpose to maintain cellular homeostasis and, from a certain limit, as a factor that aggravates aging. (a) The increase in ROS levels, first as a factor that activates survival pathways, continues to increase as a consequence of the deficiency in the antioxidant system, generating other cellular responses such as apoptosis, with a failure in apoptotic signalling, and driving towards severe cellular damage, such as necrosis. (b) Several sources of ROS contribute to the increase of redox potential, a factor that shifts the balance to the transcription of pro-inflammatory factors, while the antioxidant genes are silenced, connecting ROS and inflammation to aging. 
accompanying aging, and directly proportional to the increase in cellular dysfunction (Figure 4(b)).

The main source of ROS during aging is the mitochondria [78]. Harman in 1972, reviewed his theory about free radicals after the discovery that mitochondria turned oxygen into water, a process that, when deficient, results in a high production of superoxide anions, raising mitochondrial ROS (mtROS) levels, which lead to the accumulation of mitochondrial DNA (mtDNA) mutations, driving towards mitochondrial dysfunction, resulting in aging [79]. However, recent evidences involving mtROS using longevity animals modelling reject, at least in part, the original idea of the mitochondrial theory of aging [62]. These pathways conserved from yeast to mammals have been subsequently assessed for their role in regulating longevity, as well as to their roles played in CVDs [80].

Studies with $C$. elegans report that, by deletion of the SOD2 gene, the increase in mtROS seems to prolong lifespan [81]. In Drosophila, mtROS from the electron transport chain also appears to have a positive effect on the lifespan [82]. In addition, overexpression of catalase increases resistance to oxidative stress but do not improve lifespan [83]. In worms, antioxidant diets reduce their lifespan [84]. In mice, genetic alterations that increase mtROS and oxidative damage do not accelerate aging, although induce the appearance of various age-related diseases [85]. There is evidence that mtROS and cytosolic ROS have opposite effects, being the cytosolic more toxic to the cell [86].

Therefore, the $\mathrm{H}_{2} \mathrm{O}_{2}$ produced with beneficial propose in the mitochondria, eventually diffuses through the mitochondrial membrane [87], reaching to the cytoplasm contributing to the oxidative stress involved in aging, suggesting that ROS effects are dependent on where they are present and their concentration [86].

The elderly are more susceptible to oxidative stress due to a reduction in the efficiency of their endogenous antioxidant systems. Organs such as the heart, which it has a limiting rate of replication and high levels of oxygen consumption, are particularly sensitive to this phenomenon, which explains, in part, a high prevalence of CVDs in aging [88]. On the other hand, in endothelial cells, ROS derived from NADPH oxidase complex induces in vivo kinase prosurvival via AMPK, plus an additional effect of inducing autophagy, improving the vascular function in aged mice coronary [89]. Thus, this approach can integrate paradoxical concepts about the beneficial, deleterious, or neutral role of ROS in aging.

\section{Inflammation: A War without an Army}

Aging is accompanied by a systemic increase of proinflammatory agents, a phenomenon known as "inflammaging" [90]. Senescent cells have the ability to release proinflammatory agents (ASAP) capable of attracting defence cells, that phagocyted the senescent cells [91, 92]. However, in aging, the exhaustion of stem cells occurs, reducing the regenerative capacity of the organism, as well as the production of functional immunity cells, a term known as immunosenescence, allowing the accumulation of senescent cells into the body, which is related to the onset of cardiovascular diseases $[8,93]$.

The ASAP components include agents such as tumor necrosis factor- $\alpha$ (TNF- $\alpha$ ), interleukin-6 (IL-6), and IL-1 $\beta$ [94]. These proinflammatory agents are mainly regulated by transcription factors sensitive to redox potential, as the activator of protein-1 (AP-1) and nuclear factor kappa B (Nf-kB) [95]. Overproduction of ROS is essential for activating AP-1 and Nf-kB through the stress of kinases such as extracellular signal regulatory kinases (ERKs), c-jun $\mathrm{N}$ terminal kinases (JNKs), p38 mitogen-activated protein kinase (p38 MAPK), protein kinase C (PKC), phosphatidylinositol-4,5 bisphosphate 3-kinase (PI3K), Akt, and Src family kinases (SFK) [96].

This leads to the increased expression of inflammatory target proteins such as matrix metalloproteinase-9 (MMP9), intercellular adhesion molecule-1 (ICAM-1), vascular cell adhesion molecule 1 (VCAM-1), inducible nitric oxide synthase (iNOS), cyclooxygenase-2 (COX-2), and cytosolic phospholipase A2 (cPLA2) and proinflammatory mediators such as the TNF- $\alpha$, IL-1, and IL-6. Many of these inflammatory proteins or their products such as iNOS, COX, and PGE2 are prominent sources of ROS [96-99]. In fact, the presence of these inflammatory biomarkers in aging is related to the endothelial damage, vascular smooth muscle cell (VSMC) proliferation, and matrix remodelling, being associated to the genesis and progression of cardiovascular diseases, such as atherosclerosis and hypertension [100-102]. Moreover, targeting the overexpression of redox-sensitive transcription factor, NF- $\kappa \mathrm{B}$, by antiinflammatory molecules seems to play positive effects on the prevention of clinical manifestations of vascular aging, the step to cardiovascular disease [103].

Therefore, one of the fundamental features associated with cardiovascular aging is the crosstalk between oxidative stress and inflammation (Figure 4(b)). It is necessary to point out that both processes contribute to the physiological organism defence, and in the young individual, these processes are with their basal functional activity. For the inflammatory signalling stimulation, it is a necessary increase in the redox potential, which is achieved by elevated ROS generation, especially regulated by the mitochondria.

\section{Mitochondrial Dysfunction: Communication Failure}

Mitochondria are considered the cellular "powerhouse," since they have the ability to generate adenosine triphosphate (ATP) through oxidative phosphorylation (OXPHOS), providing chemical energy for cellular survival and function [25]. In addition, there is evidence that mitochondria play a nonenergetic role in the regulation of metabolism, apoptosis, innate immunity, and cardiovascular aging [104-106].

Despite that most mitochondrial genes were transferred to the nuclear genome, 13 subunits essential for OXPHOS activity remain encoded by mtDNA. The other 76 subunits are encoded by nuclear genome, being synthetized in the cytoplasm and imported to the mitochondria, requiring 
functional communication between both genomes [107, 108]. This functional interaction is essential for mitochondrial health, and the failure of this communication leads to mitochondrial dysfunction, decreasing ATP synthesis [106]. In this way, the failure in energy status drives towards endothelial dysfunction, plus inflammation, and oxidative stress, being related to vascular remodelling [109]. In addition, mitochondrial dysfunction is associated to chronic oxidative stress in aged vessels and cardiomyocytes, leading to a deregulation of the cardiovascular system [110].

The mitochondrion regulation occurs mainly by peroxisome proliferator-activated receptor- $\gamma$ coactivators $\alpha$ and $\beta$ (PGC- $1 \alpha$ and PGC-1 $\beta$, resp.), which responds to changes in nutrient status, such as the ratio of $\mathrm{NAD}^{+} / \mathrm{NADH}$ and AMP/ATP (regulated through SIRT1 and AMPK, resp.) $[111,112]$. The expression of PGC- $1 \alpha / \beta$ plays a fundamental role in mitochondrial biogenesis, protecting the vascular endothelium and consequently promoting vascular homeostasis $[113,114]$.

Recently, Gomes and colleagues described a process of mitochondria regulation via $\mathrm{HIF}-1 \alpha$, independent of PGC$1 \alpha / \beta$, in response to SIRT1 activity, which it is controlled by nuclear $\mathrm{NAD}^{+}$levels. Six hours after induction of the deletion of the SIRT1 gene in myoblasts, HIF- $1 \alpha$ levels begin to rise, and after 12 hours, loss of mitochondrial homeostasis occurs, although ROS levels only increase after 24 hours of the procedure [115]. This HIF- $\alpha$-mediated ROS in C. elegans is the main determinant of lifespan, but the mechanisms involved are still not fully understood [116].

In aging, there is no loss in SIRT1 levels in the body, but $\mathrm{NAD}^{+}$levels decrease with age, leading to a downregulation of SIRT1 activity [117]. As a result, a pseudohypoxic state occurs, decreasing the activity of complexes I, III, IV, and V (encoded by nuclear and mitochondrial genomes) but not complex II (encoded by the nuclear genome) [107]. To recover the activity of complexes I, III, IV, and V, it is necessary to restore mtDNA and nuclear DNA communication, which is achieved by NMN supplementation $\left(\mathrm{NAD}^{+}\right.$precursor). Treatments that restore $\mathrm{NAD}^{+}$levels have been shown to be beneficial in restoring mitochondrial function and several aspects related to aging in mice $[115,117,118]$, indicating that aging is, at least in part, caused by a failure in nuclear-mitochondrial communication, a process that is dependent of energetic cellular balance $[112,115]$.

Treatments that promote mitochondrial health drive towards an improvement in metabolism and heath aging and are related to several benefits on the cardiovascular system [119-121]. In addition, targeting mitochondria seems to have positive effects on the cardiovascular system [122].

In a wide perspective, it is possible to identify that a failure in the cellular energy creates a stressful environment that eventually leads to senescence (Figure 5). The ROS increased with the mission of stimulating survival mechanisms and also promote DNA damage, driving towards aging. It is still not clear whether the relation between ROS and $\mathrm{NAD}^{+}$levels in vascular cells could help to understand the increased redox potential in these cells. Moreover, to maintain the energy status in satisfactory levels, mechanisms that counteract ATP depletion, such as autophagy, play a fundamental role in protecting cells from the energy failure due to mitochondrial dysfunction.

\section{Autophagy: Cellular Scavengers}

Autophagy or "self-eating" refers to the lysosomal degradation process that removes protein aggregates, damaged organelles, toxic substances, and even pathogens [123]. This process is essential to maintain cell integrity and homeostasis by providing metabolites for cell survival under stress conditions [124]. In addition, it helps to maintain cellular energy levels during nutrient limitations through catabolic recycling processes [125].

There are three types of autophagy currently described as macroautophagy, microautophagy, and chaperone-mediated autophagy (CMA). All differ in their mechanisms and functions [126]. Microautophagy produces random invaginations in the lysosomal membrane, involving nearby cytoplasmic components to the lysosomal lumen [127]. CMA acts directly through the lysosomal membrane via the specific receptor, LAMP-2A (lysosomal-associated membrane with protein type 2) [128]. Macroautophagy, often referred as autophagy, requires formation of a double membrane (autophagosome) involving the material to be degraded and subsequently being fused to the lysosome (Figure 6) [129].

Autophagy is mainly downregulated by the mammalian target of rapamycin (mTOR) complex. This mTOR complex is activated under nutrient-rich conditions, playing a fundamental role in the nutrient sensitivity [130]. In a nutrientpoor condition, another energetic sensor is activated, AMPK, which directly inhibits mTOR by its direct phosphorylation as well as directly activates the ULK1 (ATG protein family) (ATG, genes related to autophagy), stimulating autophagy [129]. The nutrient shortage also regulates the autophagy at the transcriptional level by modulating the expression of ATG-encoded genes, and this mechanism is mediated, at least in part, by the transcription factor FOXO1 [131].

In aging, autophagy is deregulated or inoperative, favoring the accumulation of "garbage" into the cell [132]. Overexpression of mTOR complex during aging increases abnormal protein aggregates, being related to the genesis of CVDs [133]. On the other hand, enhancing autophagy by mTOR inhibition or AMPK activation leads to an increase in healthspan, improving the cardiovascular function and prevents CVDs $[134,135]$. However, its excessive autophagy activation seems to have a deleterious effect on the cardiovascular system [136]. Thereby, autophagy seems to be a compensatory effect on cellular energy levels that depend on mitochondrial dysfunction, and to understand the crosstalk between both regulators is essential to connect the energetic signalling to metabolism.

\section{Metabolic Control of Aging: Connecting the Dots}

Aging is characterized by a decrease in cellular energy supply [7]. The major regulators of this process are the mitochondria as a source of ATP and the lysosomes, an essential organelle for the autophagy, one of the mechanisms 


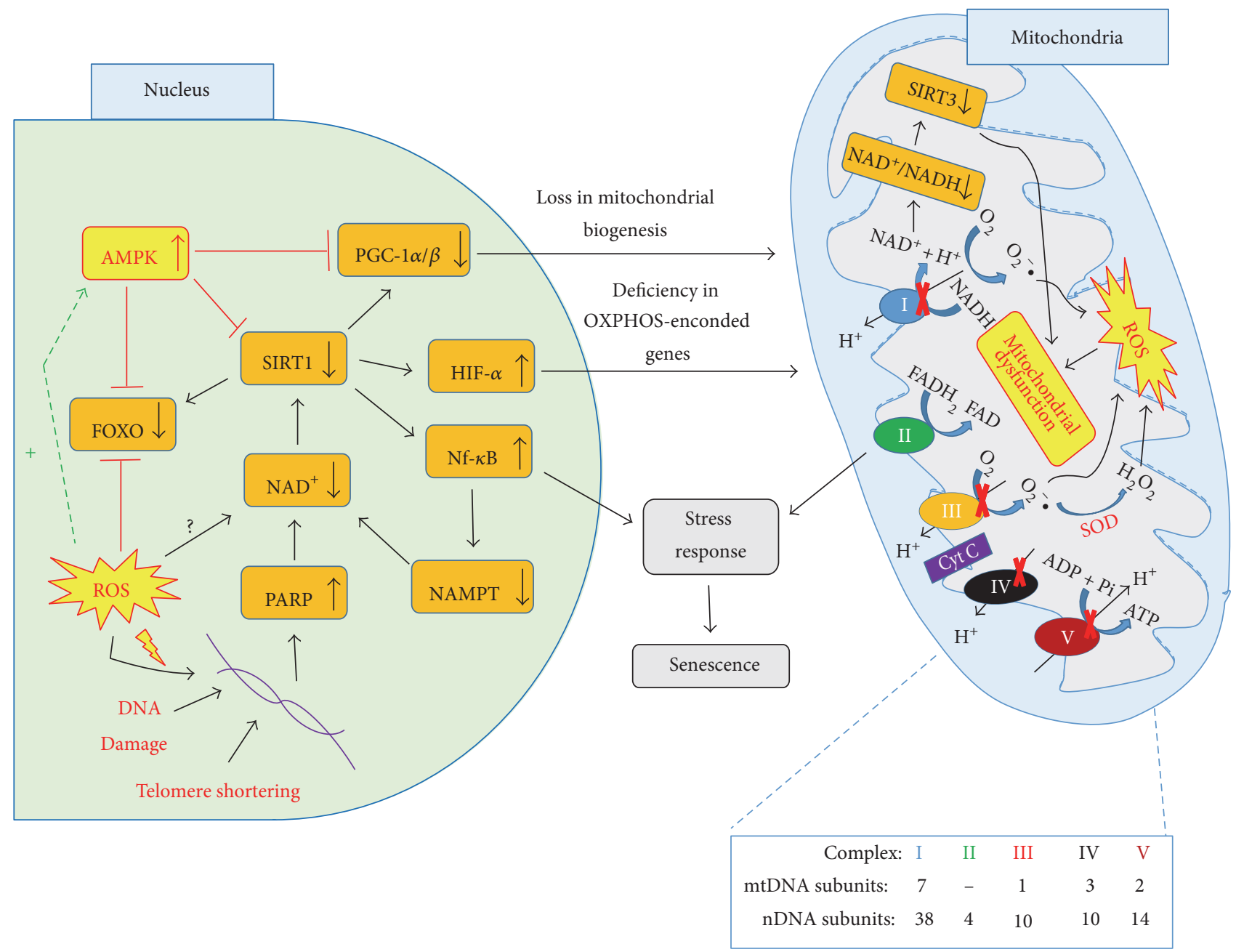

FIgURE 5: Schematic overview of nucleus-mitochondria communication in aging. Decreased SIRT1 activity due to decreased NAD ${ }^{+}$levels leads to changes in various gene expression. (1) Decreased PGC- $1 \alpha / \beta$ levels, leading to decline the mitochondria biogenesis. (2) Increased expression of HIF- $\alpha$, leading to a pseudohypoxia state and, consequently, a missed nucleus-mitochondria communication, driving towards a failure in coding OXPHOS genes. (3) Increased expression of Nf-kB levels, leading to inflammation, plus decreasing NAMPT production, a precursor of $\mathrm{NAD}^{+}$. (4) Decreased expression of FOXO, a factor that participates in cytoprotection. These responses are accompanied by increased ROS levels, a factor that activates AMPK, acting together as factors that counteract the decrease of SIRT1 activity. Increasing the ROS levels from a certain limit promote DNA damage, creating a paradoxical effect. In the mitochondria, the failure in the OXPHOS leads to a decrease in energy supply and, combined with oxidative stress, drive towards mitochondrial dysfunction. These factors combined lead to cellular stress and consequently to senescence. The interaction of oxidative stress and NAD ${ }^{+}$ levels are still unclear and may be an important source to understand how redox potential controls cellular energy metabolism.

responsible for generating energy in times of nutrient scarcity $[137,138]$. Several mechanisms that enhance the function of these processes play a beneficial role in lifespan and healthspan $[132,139]$. The mechanism involved in this process has several regulators such as insulin/IGF-1, mTOR, AMPK, and sirtuins [140]. Other factors such as ROS and p53 pathway also appear to be part of cellular energy control (Figure 7) [141, 142].

The insulin/growth factor-1 (IGF-1) pathway controls survival, proliferation, and metabolic processes. This mechanism is one of the well-characterized pathways of lifespan, conserved from yeast to mammals [143]. Low levels of insulin and IGF-1 induced by caloric restriction (CR) or metformin are associated with improved healthspan and increased longevity [140]. Interestingly, humans with exceptional longevity present low IGF-1 [144]. This effect on lifespan is, at least in part, due to the fact that IGF-1 promotes an intracellular pathway mediated by PI3K-AKT, allowing the phosphorylation of proteins known as Forkhead box O (FOXO) [145].

The AKT-mediated phosphorylation of FOXO promotes its exclusion from the nucleus to the cytoplasm, suppressing gene transcription dependent on FOXO proteins [146]. In addition, the FOXO family is sensitive to the redox potential, being ROS levels' positive modulators for their activity [147]. The FOXO family comprises evolutionarily conserved isoforms (FOXO1, FOXO3, FOXO4, and FOXO6 in mammals, DAF-16 in C. elegans, and DFOXO in D. melanogaster), and 


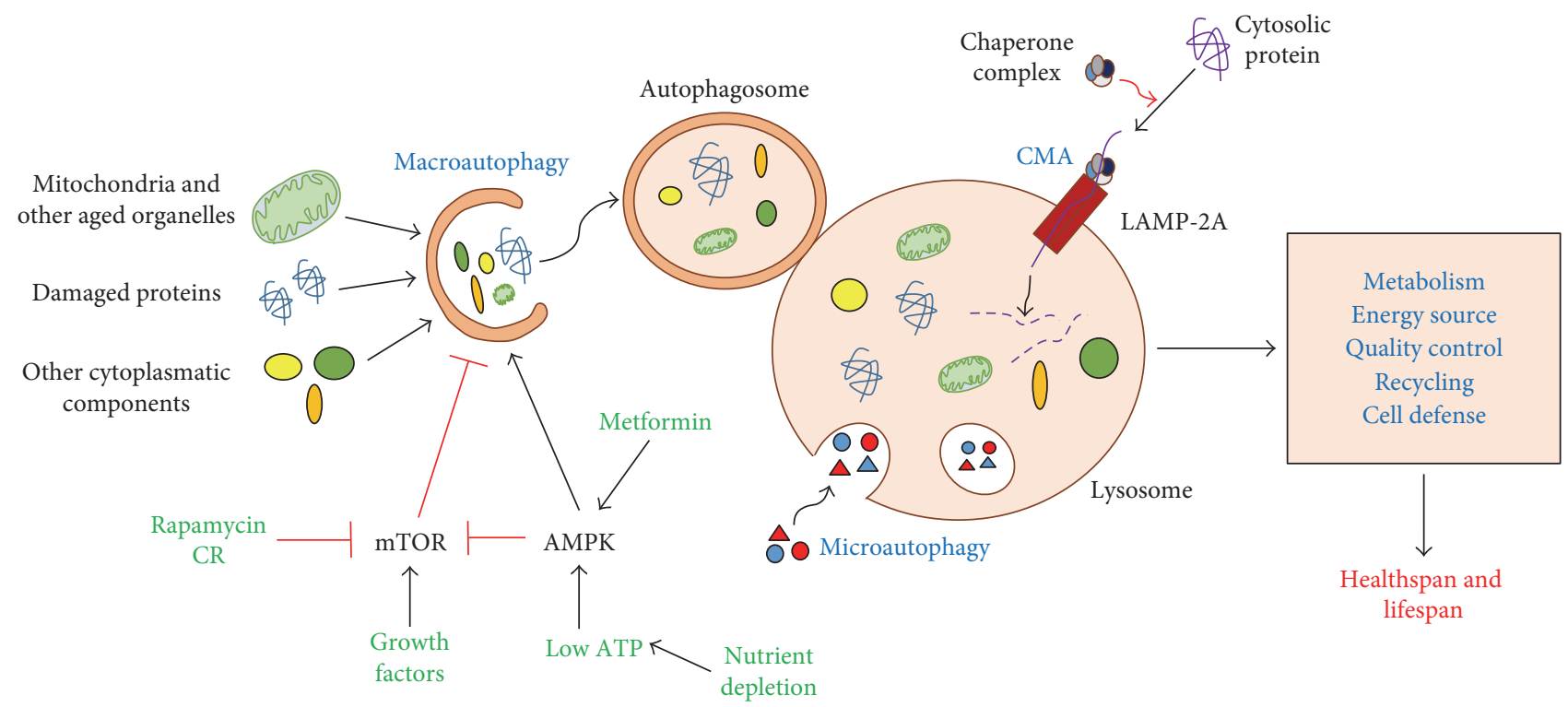

FIGURE 6: Role of autophagy as cellular scavengers. Autophagy is mainly regulated by two energy sensors: mTOR and AMPK. mTOR is an inhibitor of autophagy and is activated when there are abundant cellular nutrients. AMPK is activated when nutrients deplete, inducing autophagy by inhibiting mTOR, as well as direct activation of autophagy. This mechanism is important for cell "cleaning," degrading damaged organelles, protein aggregates, and other cellular toxic components. After the formation of the autophagosome, there is fusion with the lysosome, occurring the cleavage of the degraded material. There are two other types of autophagy: microautophagy, with direct involvement of the material by the lysosome. In addition, there is a chaperone-mediated autophagy, encompassing the material via the LAMP-2A receptor. Together, these mechanisms improve metabolism, being an energy source through recycling amino acids and, eventually, participating in cellular quality control, which promotes an improvement in the individual lifespan and healthspan.

its activity is related to various cellular processes including glucose metabolism, cell differentiation, apoptosis, DNA repair, and cellular detoxification [146, 148].

The protein kinase mTOR (mammalian target of rapamycin) is an atypical serine/threonine kinase that exerts its main cellular functions by interacting with specific adaptor proteins to form two different multiprotein complexes, mTOR complex 1 (mTORC1) and mTOR complex 2 (mTORC2) [149]. The mTOR complex is one of the major cellular regulators of nutrient sensitivity, being activated in the presence of growth factors and in abundances of cellular nutrients [130]. In aging, increased mTOR activity is linked to senescence and autophagy deficiency. Treatment with compounds, such as rapamycin delay replicative senescence, reduces senescence induced by DNA damage and reduces mitochondrial dysfunction by inhibit the mTOR complex $[150,151]$.

AMPK is another master regulator to cellular energy status [152]. In mammals, it is activated when the AMP/ ATP and ADP/ATP ratio is elevated, which occurs when ATP production is compromised. Under this circumstance, its response has the purpose to activate alternative catabolic ATP-producing pathways, plus by inhibiting ATPconsuming processes $[152,153]$. Thus, AMPK activates a series of compensatory responses including fatty acid oxidation ( $\beta$-oxidation), inhibition of fatty acid synthesis, increased mitochondrial biogenesis, and stimulation of glucose uptake [154]. Treatment with compounds that increases AMPK levels, such as metformin, has been shown to be beneficial in longevity, insulin resistance, and increase in physical performance [155]. In addition, there is evidence that AMPK activation increases the lifespan and is related to the improvement of metabolism in mice [5]. However, how AMPK acts on aging is quite complex and still remains to be clarified.

Sirtuins (SIRTs), the homologue of silent information regulator 2 (Sir2) present in Saccharomyces cerevisiae, consist of a family of essential proteins for mechanisms of cell defence. These proteins require $\mathrm{NAD}^{+}$for its activation [156]. In mammals, there are seven subtypes, located in different cellular compartments: nucleus (SIRT1, SIRT6, and SIRT7), cytosol (SIRT2), and mitochondria (SIRT3, SIRT4, and SIRT5) [157]. This family regulates a range of cellular events including metabolism, apoptosis, energy supply, cell survival, development, cellular differentiation, inflammation, and healthy aging [158, 159]. In aging, SIRT1 stimulates cardioprotection, inducing resistance against hypertrophic and oxidative stress, also inhibits cardiomyocyte apoptosis, and regulates cardiac metabolism [160]. SIRT1 activation induced by CR improves heart protection from ischemia/reperfusion, and this effect is abolished in SIRT1 knockout mice [161]. In addition, compounds that are able to induce SIRT1 activation, such as resveratrol, also appear to induce cardioprotection by reducing ROS production $[160,162]$.

The $\mathrm{p} 53$ protein is known to induce a range of antiproliferative processes, such as cell cycle arrest, leading to senescence and apoptosis in response to cellular stress [163]. In addition, p53 plays a critical role in monitoring and modulating cellular metabolic status, controlling, at least in part, 


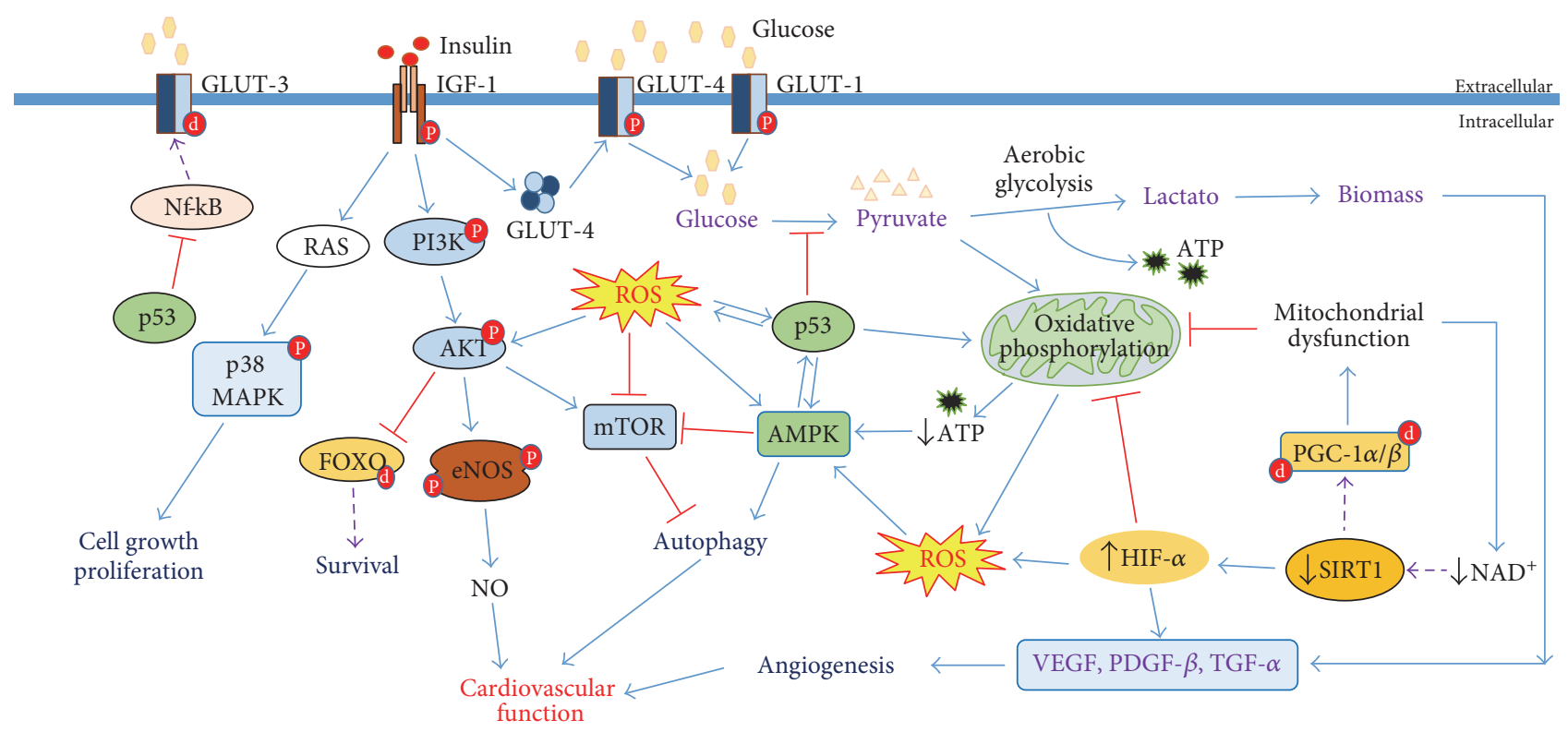

$\begin{aligned} \longrightarrow & \text { Activators } \\ -\rightarrow & \text { Less active } \\ - & \text { Inhibitors }\end{aligned}$

FIgURE 7: Metabolic control involved in aging and on the cardiovascular system. IGF-1, mTOR, AMPK, SIRT1, p53, and ROS are key regulators in metabolic control. Many of these pathways are complex involving crosstalk between them, with many paradoxical effects. The stimulation of the IGF-1 pathway by insulin promotes PI3K/AKT pathway activation, which induces the exclusion of FOXO from the nucleus, inhibiting its function; in addition, IGF-1 activates eNOS, increasing NO availability, improving the vascular function. IGF-1 also activates the RAS/p38MAPK pathway inducing mechanisms of cell growth and proliferation. Finally, IGF-1 stimulates vesicles containing GLUT-4 to the cell membrane, promoting the uptake of glucose, the main cellular energy substrate. There are also other two glucose transporters that help in glucose uptake such as GLUT-1 and GLUT-3; the last one can be downregulated by p53 via Nf-kB. Under normal conditions, mostly, pyruvate is directed to the mitochondria, producing ATP by OXPHOS. In age, NAD ${ }^{+}$levels decrease, driving towards a loss in SIRT1 activity, resulting in mitochondrial dysfunction via PGC- $1 \alpha / \beta$ and HIF- $\alpha$. Thus, pyruvate is directed to lactate production, even in the presence of $\mathrm{O}_{2}$, a process known as "the Warburg effect". This metabolic shift is essential for increasing biomass, stimulating cell growth, proliferation, and differentiation, which promote angiogenesis. In this way, a mitochondrial dysfunction results in a decreased ATP production, activating AMPK. This protein stimulates autophagy, generating energy for the cell. In addition, it stimulates p53, which inhibit the uptake and conversion of glucose, to stimulate OXPHOS activity, generating an antiproliferative effect. Finally, ROS produced by mitochondrial dysfunction stimulates several signalling pathways, such as AMPK, but also activates AKT, which stimulates mTOR, being the redox potential the major regulator of this balance.

processes such as glycolysis, oxidative phosphorylation, insulin sensitivity, mitochondrial integrity, fatty acid oxidation, and autophagy $[164,165]$.

p53 counteracts glycolysis by directly inhibiting the expression of GLUT1 and GLUT4 glucose transporters $[166,167]$ and indirectly by inhibiting GLUT3 via Nf-kB, resulting in a decrease in glucose uptake [168]. In addition, p53 controls a wide range of proteins that participate in glycolysis, acting as a glycolytic activity regulator [169, 170]. On the other hand, p53 promotes oxidative phosphorylation by inducing the expression of cytochrome $\mathrm{c}$ oxidase 2 (SCO2) and inhibits pyruvate dehydrogenase kinase 2 (PDK2) through parkin (PARK2), regulating mitochondrial respiration $[171,172]$. Thus, $\mathrm{p} 53$ protein acts by connecting the cellular energy supply and senescent stage, being one of the most important regulators for the aging process $[141,173,174]$. The same mechanisms that lead to aging described above can be implicated on the cardiovascular system, being related to the balance between health and diseases, including CVDs.

\section{Aging: Implications on the Cardiovascular System}

Cardiovascular aging is defined as an age-dependent progressive degeneration, which makes the heart and vessels more vulnerable to stress, contributing to increased mortality and morbidity [175]. Notably, the vascular aging is characterized by molecular, structural, cellular, and physiological changes, being aging the main risk factor in the pathogenesis of CVDs [176, 177].

In the aged heart, several complex modifications including diastolic dysfunction, left ventricular hypertrophy, increased risk of atrial fibrillation, and valvular degeneration lead to a decreased exercise capacity, which is related to heart failure [178]. 


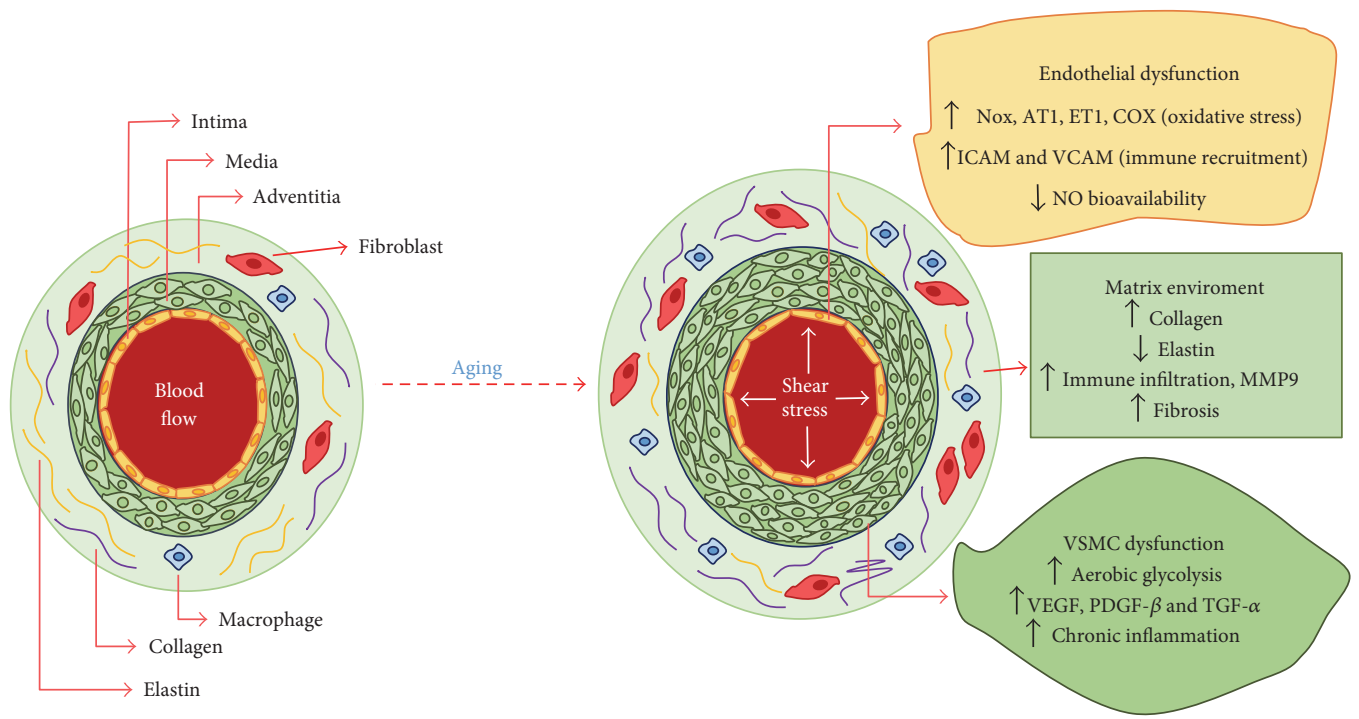

(a)

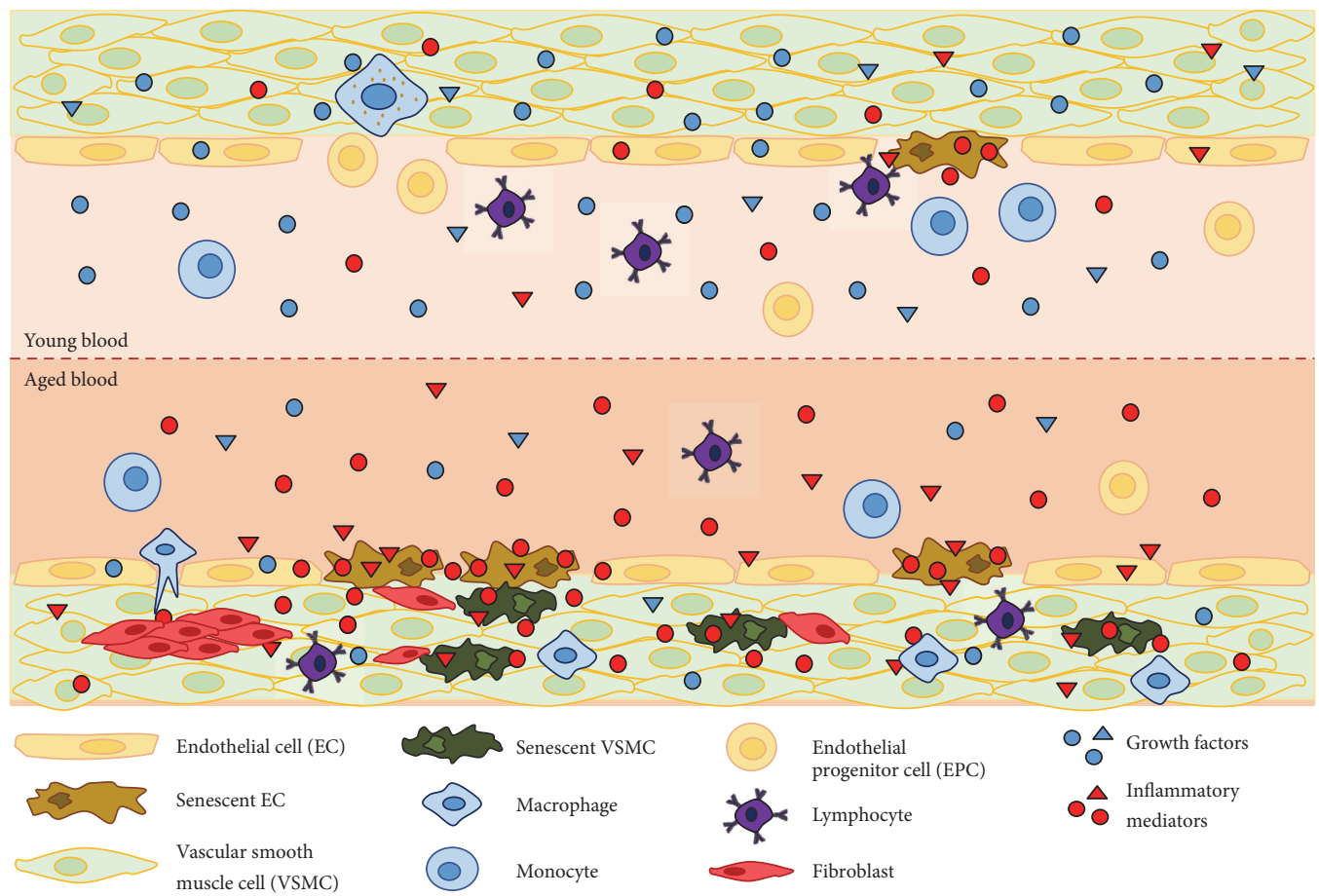

(b)

FIGURE 8: Young and aged vascular comparison in two different perspectives. In vascular aging, the remodelling occurs due to the accumulation of senescent and dysfunctional cells in response to the environmental changes caused by age. (a) In the aged vessel, there is a loss of the vessel elasticity, due to the raises of contracting factors, plus an increase in the number of muscle cells. These factors combined drive towards the matrix change, with inflammatory infiltrates and fibrosis, leading to vascular hypertrophy. (b) In young blood, there is a predominance of growth factors, in addition to healthy cells of immunity and progenitor cells driving towards vascular "cleaning" and regeneration, respectively. In the aged blood, it is checked that there is a predominance in proinflammatory factors, released largely by senescent cells. The senescent cells accumulate with age in response to a failure of the immune system, a term known as immunosenescence. In addition, there is an increase in fibroblast proliferation, leading to a stressful environment related to the vascular remodelling.

Under normal conditions, vessels have the ability to respond to various stimuli, such as vasoconstriction due to an adrenergic or circulatory (e.g., angiotensin II or endothelin II) agonist response [179]. On the other hand, vasodilator mediators such as nitric oxide (NO), endothelium-derived hyperpolarizing factor (EDHF), and some prostaglandins (e.g., PGI2) have the mission of balancing the vascular tonus $[180,181]$.

In fact, the production of NO is the major marker of the vascular function $[182,183]$. In the vessel, its synthesis 
is made mainly by endothelial nitric oxide synthase (eNOS), being aging associated to a decrease in the NO production [184-186]. In senescent-accelerated mice, endothelial dysfunction associated with aortic age is linked to eNOS dysfunction [187]. Increased release of ROS and subsequent inactivation of $\mathrm{NO}$ are important mechanisms involved on the impairment of endothelium-dependent vessel relaxation, leading to stiffness and vascular inflammation [188, 189].

The vascular aging leads to thickening of the intima and media layer (vascular remodelling), as well as gradual loss of arterial elasticity, resulting in vascular rigidity [190, 191]. Increased collagen and decreased elastin content, promoted at least in part by age, in addition to increased glycosylated proteins, matrix metalloproteinase activity, and systemic stimuli such as angiotensin II signalling, are linked to vascular rigidity [192, 193].

Aged endothelial cells (ECs) and VSMCs also show increased secretion of proinflammatory cytokines, derived in large part from senescent cells, which results in persistent vascular inflammation [30, 101]. In addition, VSMCs change their metabolic route to promote aerobic glycolysis (in response to mitochondrial dysfunction), being essential to produce a high rate of substrate for cellular growth and proliferation, and to express factors such as vascular endothelial growth factor (VEGF), platelet-derived growth factor (PDGF- $\beta$ ), and transforming growth factor alpha (TGF- $\alpha$ ) that contribute to the vascular remodelling (Figure 8(a)) [194, 195].

The vasculature also plays an important role in connecting all the tissues through the blood flow. In fact, the vascular inflammation extends to other organism components leading to a systemic effect [196]. In the young blood, there is a predominance of growth factors in detriment of inflammatory mediators, plus healthy immunity cells and endothelial progenitor cells, which are essential for vascular "cleaning" and regeneration [197]. On the other hand, aged blood has predominance of proinflammatory factors, largely released by senescent cells [198]. In addition, there is a failure of the immune system, resulting in the accumulation of senescent cells in the vascular tissue, leading to a stressful environment, which is associated with the development and progression of CVDs [196, 199].

An elegant study performed by Loffredo and colleagues [200] demonstrated that changing the systemic influence from the blood by connecting young to aged blood by parabiosis (surgical technique that unites the vasculature of two living animals) showed that after 4 weeks, aged rats that were exposed to young circulation had reversed age-related cardiac hypertrophy, resulting in cardiovascular protection.

Thus, the vascular remodelling, by aging or pathological conditions, is accompanied by oxidative stress and inflammation, leading to an increase of senescent cells in these tissues (Figure 8(b)) [59, 201]. The endothelial cells have fundamental importance in the development of vascular remodelling, being an endothelial dysfunction target of therapies against CVDs, such as hypertension, atherosclerosis, and heart failure [202-204]. Treating aging seems to show several benefits on the cardiovascular system, by creating a healthy systemic environment, which slows the progression of endothelial dysfunction and the vascular remodelling associated with aging, leading to cardiovascular protection.

\section{Conclusion and Future Directions}

In this review, we discuss cellular mechanisms related to aging. It is possible to notice that aging is a multifactorial process that encompasses intrinsic factors to several species and the accumulation of senescent cells is common in the main part of them. Understanding the aging process, we may find the genesis of age-related diseases, since many of them are characterized by disorders that are consequences of cellular dysfunction caused by senescence. This accumulation of senescent cells can have a replicative genesis, bringing into action therapeutic targets such as telomerase, as well as induced by stress, such as the cellular energetic loss, which encompasses the mitochondria dysfunction and deregulated autophagy. These mechanisms are connected by a series of proteins, transcription factors, and environmental factors into the cell, such as redox potential. However, a determinant factor controlling the whole process remains unclear. One of the candidates would be to understand how the redox potential determines gene expression and promotes responses in metabolism. The fact that ROS promotes an increase in redox potential and this hallmark is involved in aging as well as in age-related diseases makes us believe that the increase in cellular ROS is intentional by the cells, in order to promote cellular survival mechanisms, requiring more and more ROS to have the same effect over time, a process that drives towards the deleterious effects of ROS. Understanding how the concentration and localization of ROS and its interaction with longevity genes may be a key point to understand the complex metabolic mechanism that controls aging. In this way, it will be possible, in the future, to take a pill that promotes an increase in longevity and, in addition, play a role in minimizing the onset of aging-related diseases.

\section{Disclosure}

The authors are responsible for the content and writing of this paper.

\section{Conflicts of Interest}

The authors report no conflict of interests.

\section{Authors' Contributions}

The three authors equally contributed to the composition of the manuscript.

\section{Acknowledgments}

Financial supports from Instituto UFPB de Desenvolvimento da Paraíba (IDEP) and Conselho Nacional de Desenvolvimento Científico e Tecnológico (CNPq, Grant no. 401591/2013-1) are gratefully acknowledged. 


\section{References}

[1] UN, "UNDESA Population Division, World population prospects: the 2015 revision," HelpAge, Global AgeWatch Index 2015: Insight Report, HelpAge International, London WC1A 9GB, UK, 2015.

[2] WHO, NCD Mortality and Morbidity, World Health Organization, 2012, http://www.who.int/gho/ncd/mortality_morbi dity/en/.

[3] J. Campisi, “Aging, cellular senescence, and cancer," Annual Review of Physiology, vol. 75, no. 1, pp. 685-705, 2013.

[4] C. López-Otín, M. A. Blasco, L. Partridge, M. Serrano, and G. Kroemer, "The hallmarks of aging," Cell, vol. 153, no. 6, pp. 1194-1217, 2013.

[5] C. E. Riera, C. Merkwirth, C. D. D. M. Filho, and A. Dillin, "Signaling networks determining life span," Annual Review of Biochemistry, vol. 85, no. 1, pp. 35-64, 2016.

[6] J. Campisi and F. d'Adda di Fagagna, "Cellular senescence: when bad things happen to good cells," Nature Reviews Molecular Cell Biology, vol. 8, no. 9, pp. 729-740, 2007.

[7] D. V. Ziegler, C. D. Wiley, and M. C. Velarde, "Mitochondrial effectors of cellular senescence: beyond the free radical theory of aging," Aging Cell, vol. 14, no. 1, pp. 1-7, 2015.

[8] A. Sagiv and V. Krizhanovsky, "Immunosurveillance of senescent cells: the bright side of the senescence program," Biogerontology, vol. 14, no. 6, pp. 617-628, 2013.

[9] J. R. Aunan, M. M. Watson, H. R. Hagland, and K. Søreide, "Molecular and biological hallmarks of ageing," British Journal of Surgery, vol. 103, no. 2, pp. e29-e46, 2016.

[10] R. Vicente, A. L. Mausset-Bonnefont, C. Jorgensen, P. LouisPlence, and J. M. Brondello, "Cellular senescence impact on immune cell fate and function," Aging Cell, vol. 15, no. 3, pp. 400-406, 2016.

[11] A. L. Gruver, L. L. Hudson, and G. D. Sempowski, "Immunosenescence of ageing," The Journal of Pathology, vol. 211, no. 2, pp. 144-156, 2007.

[12] M. Collado, M. A. Blasco, and M. Serrano, "Cellular senescence in cancer and aging," Cell, vol. 130, no. 2, pp. 223233, 2007.

[13] J. Oh, Y. D. Lee, and A. J. Wagers, "Stem cell aging: mechanisms, regulators and therapeutic opportunities," Nature Medicine, vol. 20, no. 8, pp. 870-880, 2014.

[14] M. Abbas, L. Jesel, C. Auger et al., "Endothelial microparticles from acute coronary syndrome patients induce premature coronary artery endothelial cell aging and thrombogenicity: role of the Ang II/AT1 receptor/NADPH oxidase-mediated activation of MAPKs and PI3-kinase pathways," Circulation, vol. 135, no. 3, pp. 280-296, 2017.

[15] D. Munoz-Espin and M. Serrano, "Cellular senescence: from physiology to pathology," Nature Reviews Molecular Cell Biology, vol. 15, no. 7, pp. 482-496, 2014.

[16] F. Lanigan, J. G. Geraghty, and A. P. Bracken, “Transcriptional regulation of cellular senescence," Oncogene, vol. 30, no. 26, pp. 2901-2911, 2011.

[17] D. J. Baker, B. G. Childs, M. Durik et al., "Naturally occurring p16Ink4a-positive cells shorten healthy lifespan," Nature, vol. 530, no. 7589, pp. 184-189, 2016.

[18] G. P. Dimri, X. Lee, G. Basile et al., "A biomarker that identifies senescent human cells in culture and in aging skin in vivo," Proceedings of the National Academy of Sciences, vol. 92, no. 20, pp. 9363-9367, 1995.
[19] M. Althubiti, L. Lezina, S. Carrera et al., "Characterization of novel markers of senescence and their prognostic potential in cancer," Cell Death \& Disease, vol. 5, article e1528, 2014.

[20] S. Khemais-Benkhiat, N. Idris-Khodja, T. P. Ribeiro et al., "The redox-sensitive induction of the local angiotensin system promotes both premature and replicative endothelial senescence: preventive effect of a standardized Crataegus extract," The Journals of Gerontology: Series A, vol. 71, no. 12, pp. 1581-1590, 2016.

[21] D. G. A. Burton and V. Krizhanovsky, "Physiological and pathological consequences of cellular senescence," Cellular and Molecular Life Sciences, vol. 71, no. 22, pp. 4373-4386, 2014.

[22] P. D. Adams, "Healing and hurting: molecular mechanisms, functions, and pathologies of cellular senescence," Molecular Cell, vol. 36, no. 1, pp. 2-14, 2009.

[23] C. B. Harley, A. B. Futcher, and C. W. Greider, "Telomeres shorten during ageing of human fibroblasts," Nature, vol. 345, no. 6274, pp. 458-460, 1990.

[24] A. Bernadotte, V. M. Mikhelson, and I. M. Spivak, "Markers of cellular senescence. Telomere shortening as a marker of cellular senescence," Aging (Albany New York), vol. 8, no. 1, pp. 3-11, 2016.

[25] L. Yue and H. Yao, "Mitochondrial dysfunction in inflammatory responses and cellular senescence: pathogenesis and pharmacological targets for chronic lung diseases," British Journal of Pharmacology, vol. 173, no. 15, pp. 2305-2318, 2016.

[26] C. D. Wiley, M. C. Velarde, P. Lecot et al., "Mitochondrial dysfunction induces senescence with a distinct secretory phenotype," Cell Metabolism, vol. 23, no. 2, pp. 303-314, 2016.

[27] D. A. Gewirtz, "Autophagy and senescence," Autophagy, vol. 9, no. 5, pp. 808-812, 2013.

[28] P. Davalli, T. Mitic, A. Caporali, A. Lauriola, and D. D'Arca, "ROS, cell senescence, and novel molecular mechanisms in aging and age-related diseases," Oxidative Medicine and Cellular Longevity, vol. 2016, Article ID 3565127, 18 pages, 2016.

[29] M. D. Ross, E. Malone, and G. Florida-James, "Vascular ageing and exercise: focus on cellular reparative processes," Oxidative Medicine and Cellular Longevity, vol. 2016, Article ID 3583956, 15 pages, 2016.

[30] J. C. Wang and M. Bennett, "Aging and atherosclerosis: mechanisms, functional consequences, and potential therapeutics for cellular senescence," Circulation Research, vol. 111, no. 2, pp. 245-259, 2012.

[31] T. Tchkonia, Y. Zhu, J. v. Deursen, J. Campisi, and J. L. Kirkland, "Cellular senescence and the senescent secretory phenotype: therapeutic opportunities," The Journal of Clinical Investigation, vol. 123, no. 3, pp. 966-972, 2013.

[32] F. Fyhrquist, O. Saijonmaa, and T. Strandberg, "The roles of senescence and telomere shortening in cardiovascular disease," Nature Reviews Cardiology, vol. 10, no. 5, pp. 274$283,2013$.

[33] L. Hayflick and L. Moorhead, "The serial cultivation of human diploid cell strains," Experimental Cell Research, vol. 25, pp. 585-621, 1961.

[34] J. Maciejowski and T. d. Lange, “Telomeres in cancer: tumour suppression and genome instability," Nature Reviews Molecular Cell Biology, vol. 18, no. 3, pp. 175-186, 2017.

[35] C. A. Armstrong and K. Tomita, "Fundamental mechanisms of telomerase action in yeasts and mammals: understanding telomeres and telomerase in cancer cells," Open Biology, vol. 7, no. 3, article 160338, 2017. 
[36] P. J. Hohensinner, J. J. Goronzy, and C. M. Weyand, "Telomere dysfunction, autoimmunity and aging," Aging and Disease, vol. 2, no. 6, pp. 524-537, 2011.

[37] K. Muraki, K. Nyhan, L. Han, and J. P. Murnane, "Mechanisms of telomere loss and their consequences for chromosome instability," Frontiers in Oncology, vol. 2, 2012.

[38] E. H. Blackburn, E. S. Epel, and J. Lin, "Human telomere biology: a contributory and interactive factor in aging, disease risks, and protection," Science, vol. 350, no. 6265, pp. 1193-1198, 2015.

[39] W. Wright and J. Shay, "The two-stage mechanism controlling cellular senescence and immortalization," Experimental Gerontology, vol. 27, pp. 383-389, 1992.

[40] M. T. Hayashi, A. J. Cesare, J. A. J. Fitzpatrick, E. LazzeriniDenchi, and J. Karlseder, "A telomere dependent DNA damage checkpoint induced by prolonged mitotic arrest," Nature Structural \& Molecular Biology, vol. 19, no. 4, pp. 387-394, 2012.

[41] J. W. Shay and W. E. Wright, "Senescence and immortalization: role of telomeres and telomerase," Carcinogenesis, vol. 26, no. 5, pp. 867-874, 2005.

[42] M. T. Hayashi, A. J. Cesare, T. Rivera, and J. Karlseder, "Cell death during crisis is mediated by mitotic telomere deprotection," Nature, vol. 522, no. 7557, pp. 492-496, 2015.

[43] J. Nandakumar and T. R. Cech, "Finding the end: recruitment of telomerase to the telomere," Nature Reviews Molecular Cell Biology, vol. 14, no. 2, pp. 69-82, 2013.

[44] D. Hockemeyer and K. Collins, "Control of telomerase action at human telomeres," Nature Structural \& Molecular Biology, vol. 22, no. 11, pp. 848-852, 2015.

[45] R. M. Marión and M. A. Blasco, "Telomeres and telomerase in adult stem cells and pluripotent embryonic stem cells," in The Cell Biology of Stem Cells, E. Meshorer and K. Plath, Eds., pp. 118-131, Springer US, Boston, MA, 2010.

[46] C. Yang, S. Przyborski, M. J. Cooke et al., "A key role for telomerase reverse transcriptase unit in modulating human embryonic stem cell proliferation, cell cycle dynamics, and in vitro differentiation," Stem Cells, vol. 26, no. 4, pp. 850$863,2008$.

[47] C. Bär and M. Blasco, "Telomeres and telomerase as therapeutic targets to prevent and treat age-related diseases [version 1; referees: 4 approved]," F1000Research, vol. 5, 2016.

[48] J.-K. Yeh and C.-Y. Wang, "Telomeres and telomerase in cardiovascular diseases," Genes, vol. 7, no. 9, p. 58, 2016.

[49] F. Sanchis-Gomar and A. Lucia, "Acute myocardial infarction: "telomerasing" for cardioprotection," Trends in Molecular Medicine, vol. 21, no. 4, pp. 203-205, 2015.

[50] C. Bär, B. B. d. Jesus, R. Serrano et al., "Telomerase expression confers cardioprotection in the adult mouse heart after acute myocardial infarction," Nature Communications, vol. 5, 2014.

[51] A. G. Panayiotou, A. N. Nicolaides, M. Griffin et al., "Leukocyte telomere length is associated with measures of subclinical atherosclerosis," Atherosclerosis, vol. 211, no. 1, pp. 176-181, 2010.

[52] A. L. Serrano and V. Andrés, "Telomeres and cardiovascular disease: does size matter?" Circulation Research, vol. 94, no. 5, pp. 575-584, 2004.

[53] S. A. Booth and F. J. Charchar, "Cardiac telomere length in heart development, function, and disease," Physiological Genomics, 2017.
[54] G. D. Richardson, D. Breault, G. Horrocks, S. Cormack, N. Hole, and W. A. Owens, "Telomerase expression in the mammalian heart," The FASEB Journal, vol. 26, no. 12, pp. 48324840, 2012.

[55] T. Z. Nazari-Shafti and J. P. Cooke, "Telomerase therapy to reverse cardiovascular senescence," Methodist DeBakey Cardiovascular Journal, vol. 11, no. 3, pp. 172-175, 2015.

[56] M. Zurek, J. Altschmied, S. Kohlgrüber, N. Ale-Agha, and J. Haendeler, "Role of telomerase in the cardiovascular system," Genes, vol. 7, no. 6, p. 29, 2016.

[57] D. Harman, "Aging: a theory based on free radical and radiation chemistry," Journal of Gerontology, vol. 11, no. 3, pp. 298-300, 1956.

[58] B. Skibska and A. Goraca, "The protective effect of lipoic acid on selected cardiovascular diseases caused by age-related oxidative stress," Oxidative Medicine and Cellular Longevity, vol. 2015, Article ID 313021, 11 pages, 2015.

[59] J. Wu, S. Xia, B. Kalionis, W. Wan, and T. Sun, "The role of oxidative stress and inflammation in cardiovascular aging," BioMed Research International, vol. 2014, Article ID 615312, 13 pages, 2014.

[60] J. Lapointe and S. Hekimi, "When a theory of aging ages badly," Cellular and Molecular Life Sciences, vol. 67, no. 1, pp. 1-8, 2010.

[61] S. Hekimi, J. Lapointe, and Y. Wen, "Taking a good look at free radicals in the aging process," Trends in Cell Biology, vol. 21, no. 10, pp. 569-576, 2011.

[62] S. Hekimi, Y. Wang, and A. Noë, "Mitochondrial ROS and the effectors of the intrinsic apoptotic pathway in aging cells: the discerning killers!," Frontiers in Genetics, vol. 7, no. 161, 2016.

[63] K. Cervantes Gracia, D. Llanas-Cornejo, and H. Husi, "CVD and oxidative stress," Journal of Clinical Medicine, vol. 6, no. 2, p. 22, 2017.

[64] K. M. Holmstrom and T. Finkel, "Cellular mechanisms and physiological consequences of redox-dependent signalling," Nature Reviews Molecular Cell Biology, vol. 15, no. 6, pp. 411-421, 2014.

[65] H. Cai and D. G. Harrison, "Endothelial dysfunction in cardiovascular diseases: the role of oxidant stress," Circulation Research, vol. 87, no. 10, pp. 840-844, 2000.

[66] D. I. Brown and K. K. Griendling, "Regulation of signal transduction by reactive oxygen species in the cardiovascular system," Circulation Research, vol. 116, no. 3, pp. 531-549, 2015.

[67] C. Peng, X. Wang, J. Chen et al., "Biology of ageing and role of dietary antioxidants," BioMed Research International, vol. 2014, Article ID 831841, 13 pages, 2014.

[68] T. W. Kensler, N. Wakabayashi, and S. Biswal, "Cell survival responses to environmental stresses via the Keap1-Nrf2-ARE pathway," Annual Review of Pharmacology and Toxicology, vol. 47, no. 1, pp. 89-116, 2007.

[69] C. Gorrini, I. S. Harris, and T. W. Mak, "Modulation of oxidative stress as an anticancer strategy," Nature Reviews Drug Discovery, vol. 12, no. 12, pp. 931-947, 2013.

[70] V. Conti, G. Corbi, V. Simeon et al., "Aging-related changes in oxidative stress response of human endothelial cells," Aging Clinical and Experimental Research, vol. 27, no. 4, pp. 547-553, 2015.

[71] M. Santillo, A. Colantuoni, P. Mondola, B. Guida, and S. Damiano, "NOX signaling in molecular cardiovascular mechanisms involved in the blood pressure homeostasis," Frontiers in Physiology, vol. 6, p. 194, 2015. 
[72] A. C. Montezano and R. M. Touyz, "Reactive oxygen species, vascular Noxs, and hypertension: focus on translational and clinical research," Antioxidants \& Redox Signaling, vol. 20, no. 1, pp. 164-182, 2013.

[73] A. Schramm, P. Matusik, G. Osmenda, and T. J. Guzik, "Targeting NADPH oxidases in vascular pharmacology," Vascular Pharmacology, vol. 56, no. 5-6, pp. 216-231, 2012.

[74] B. Lassègue, A. San Martín, and K. K. Griendling, "Biochemistry, physiology, and pathophysiology of NADPH oxidases in the cardiovascular system," Circulation Research, vol. 110, no. 10, pp. 1364-1390, 2012.

[75] S. Sriramula and J. Francis, "Tumor necrosis factor - alpha is essential for angiotensin II-induced ventricular remodeling: role for oxidative stress," PloS One, vol. 10, no. 9, article e0138372, 2015.

[76] A. C. Montezano, A. Nguyen Dinh Cat, F. J. Rios, and R. M. Touyz, "Angiotensin II and vascular injury," Current Hypertension Reports, vol. 16, no. 6, p. 431, 2014.

[77] G.-H. Liu, J. Qu, and X. Shen, "NF- $\kappa$ B/p65 antagonizes Nrf2ARE pathway by depriving CBP from Nrf2 and facilitating recruitment of HDAC3 to MafK," Biochimica et Biophysica Acta (BBA) - Molecular Cell Research, vol. 1783, no. 5, pp. 713-727, 2008.

[78] D.-F. Dai, Y. A. Chiao, D. J. Marcinek, H. H. Szeto, and P. S. Rabinovitch, "Mitochondrial oxidative stress in aging and healthspan," Longevity \& Healthspan, vol. 3, no. 1, p. 6, 2014.

[79] D. Harman, “The biologic clock: the mitochondria?" Journal of the American Geriatrics Society, vol. 20, no. 4, pp. 145-147, 1972.

[80] B. J. North and D. A. Sinclair, "The intersection between aging and cardiovascular disease," Circulation Research, vol. 110, no. 8, pp. 1097-1108, 2012.

[81] J. M. V. Raamsdonk and S. Hekimi, "Deletion of the mitochondrial superoxide dismutase sod-2 extends lifespan in Caenorhabditis elegans," PLoS Genetics, vol. 5, no. 2, article e1000361, 2009.

[82] F. Scialò, A. Sriram, D. Fernández-Ayala et al., "Mitochondrial ROS produced via reverse electron transport extend animal lifespan," Cell Metabolism, vol. 23, no. 4, pp. 725734, 2016.

[83] R. J. Mockett, A.-C. V. Bayne, L. K. Kwong, W. C. Orr, and R. S. Sohal, "Ectopic expression of catalase in Drosophila mitochondria increases stress resistance but not longevity," Free Radical Biology and Medicine, vol. 34, no. 2, pp. 207-217, 2003.

[84] V. I. Pérez, H. V. Remmen, A. Bokov, C. J. Epstein, J. Vijg, and A. Richardson, "The overexpression of major antioxidant enzymes does not extend the lifespan of mice," Aging Cell, vol. 8, no. 1, pp. 73-75, 2009.

[85] Y. Zhang, Y. Ikeno, W. Qi et al., "Mice deficient in both Mn superoxide dismutase and glutathione peroxidase-1 have increased oxidative damage and a greater incidence of pathology but no reduction in longevity," The Journals of Gerontology Series A: Biological Sciences and Medical Sciences, vol. 64A, no. 12, pp. 1212-1220, 2009.

[86] C. E. Schaar, D. J. Dues, K. K. Spielbauer et al., "Mitochondrial and cytoplasmic ROS have opposing effects on lifespan," PLoS Genetics, vol. 11, no. 2, article e1004972, 2015.

[87] E. A. Veal, A. M. Day, and B. A. Morgan, "Hydrogen peroxide sensing and signaling," Molecular Cell, vol. 26, no. 1, pp. 1-14, 2007.
[88] V. Conti, V. Izzo, G. Corbi et al., "Antioxidant supplementation in the treatment of aging-associated diseases," Frontiers in Pharmacology, vol. 7, p. 24, 2016.

[89] E. Shafique, W. C. Choy, Y. Liu et al., "Oxidative stress improves coronary endothelial function through activation of the pro-survival kinase AMPK," Aging, vol. 5, no. 7, pp. 515-530, 2013.

[90] C. Franceschi and J. Campisi, "Chronic inflammation (inflammaging) and its potential contribution to ageassociated diseases," The Journals of Gerontology Series A: Biological Sciences and Medical Sciences, vol. 69, Supplement 1, pp. S4-S9, 2014.

[91] B. Hae-Ok, L. Young-Kyoung, K. Jeong-Min, and Y. Gyesoon, "From cell senescence to age-related diseases: differential mechanisms of action of senescence-associated secretory phenotypes," $B M B$ Reports, vol. 48, no. 10, pp. 549-558, 2015.

[92] J.-P. Coppé, P.-Y. Desprez, A. Krtolica, and J. Campisi, “The senescence-associated secretory phenotype: the dark side of tumor suppression," Annual Review of Pathology: Mechanisms of Disease, vol. 5, no. 1, pp. 99-118, 2010.

[93] T. Minamino and I. Komuro, "Vascular cell senescence: contribution to atherosclerosis," Circulation Research, vol. 100, no. 1, pp. 15-26, 2007.

[94] B. Fougère, E. Boulanger, F. Nourhashémi, S. Guyonnet, and M. Cesari, "Chronic inflammation: accelerator of biological aging," The Journals of Gerontology Series A: Biological Sciences and Medical Sciences, 2016.

[95] S.-A. Manea, A. Constantin, G. Manda, S. Sasson, and A. Manea, "Regulation of Nox enzymes expression in vascular pathophysiology: focusing on transcription factors and epigenetic mechanisms," Redox Biology, vol. 5, pp. 358366, 2015.

[96] N. Sallam and I. Laher, "Exercise modulates oxidative stress and inflammation in aging and cardiovascular diseases," Oxidative Medicine and Cellular Longevity, vol. 2016, Article ID 7239639, 32 pages, 2016.

[97] C.-C. Lin, W.-N. Lin, R.-L. Cho, C.-y. Wang, L.-D. Hsiao, and C.-M. Yang, "TNF- $\alpha$-induced cPLA2 expression via NADPH oxidase/reactive oxygen species-dependent NF- $\kappa$ B cascade on human pulmonary alveolar epithelial cells," Frontiers in Pharmacology, vol. 7, no. 447, 2016.

[98] C.-C. Lin, C.-C. Yang, C.-Y. Wang et al., "NADPH oxidase/ ROS-dependent VCAM-1 induction on TNF- $\alpha$-challenged human cardiac fibroblasts enhances monocyte adhesion," Frontiers in Pharmacology, vol. 6, no. 310, 2016.

[99] M. E. Matzkin, J. G. Miquet, Y. Fang et al., "Alterations in oxidative, inflammatory and apoptotic events in short-lived and long-lived mice testes," Aging (Albany New York), vol. 8, no. 1, pp. 95-110, 2016.

[100] M. R. Bennett, S. Sinha, and G. K. Owens, "Vascular smooth muscle cells in atherosclerosis," Circulation Research, vol. 118, no. 4, pp. 692-702, 2016.

[101] M. Wang, R. E. Monticone, and E. G. Lakatta, "Proinflammation of aging central arteries," Gerontology, vol. 60, no. 6, pp. 519-529, 2014.

[102] M. A. Gimbrone and G. García-Cardeña, "Endothelial cell dysfunction and the pathobiology of atherosclerosis," Circulation Research, vol. 118, no. 4, pp. 620-636, 2016.

[103] S. C. Gupta, C. Sundaram, S. Reuter, and B. B. Aggarwal, "Inhibiting NF- $\kappa \mathrm{B}$ activation by small molecules as a 
therapeutic strategy," Biochimica et Biophysica Acta (BBA) Gene Regulatory Mechanisms, vol. 1799, no. 10-12, pp. 775-787, 2010.

[104] J. Nunnari and A. Suomalainen, "Mitochondria: in sickness and in health," Cell, vol. 148, no. 6, pp. 1145-1159, 2012.

[105] N. M. Held and R. H. Houtkooper, "Mitochondrial quality control pathways as determinants of metabolic health," BioEssays, vol. 37, no. 8, pp. 867-876, 2015.

[106] M. Gonzalez-Freire, R. d. Cabo, M. Bernier et al., "Reconsidering the role of mitochondria in aging," The Journals of Gerontology Series a: Biological Sciences and Medical Sciences, vol. 70, no. 11, pp. 1334-1342, 2015.

[107] M. T. Ryan and N. J. Hoogenraad, "Mitochondrial-nuclear communications," Annual Review of Biochemistry, vol. 76, no. 1, pp. 701-722, 2007.

[108] P. Mishra and D. C. Chan, "Mitochondrial dynamics and inheritance during cell division, development and disease," Nature Reviews Molecular Cell Biology, vol. 15, no. 10, pp. 634-646, 2014.

[109] A. Szewczyk, W. Jarmuszkiewicz, A. Koziel et al., "Mitochondrial mechanisms of endothelial dysfunction," Pharmacological Reports, vol. 67, no. 4, pp. 704-710, 2015.

[110] M. G. Rosca and C. L. Hoppel, "Mitochondrial dysfunction in heart failure," Heart Failure Reviews, vol. 18, no. 5, pp. 607622, 2013.

[111] J. R. Friedman and J. Nunnari, "Mitochondrial form and function," Nature, vol. 505, no. 7483, pp. 335-343, 2014.

[112] E. F. Fang, M. Scheibye-Knudsen, K. F. Chua, M. P. Mattson, D. L. Croteau, and V. A. Bohr, "Nuclear DNA damage signalling to mitochondria in ageing," Nature Reviews Molecular Cell Biology, vol. 17, no. 5, pp. 308-321, 2016.

[113] M. A. Kluge, J. L. Fetterman, and J. A. Vita, "Mitochondria and endothelial function," Circulation Research, vol. 112, no. 8, pp. 1171-1188, 2013.

[114] R. Ventura-Clapier, A. Garnier, V. Veksler, and F. Joubert, "Bioenergetics of the failing heart," Biochimica et Biophysica Acta (BBA) - Molecular Cell Research, vol. 1813, no. 7, pp. 1360-1372, 2011.

[115] A. P. Gomes, N. L. Price, A. J. Y. Ling et al., "Declining NAD ${ }^{+}$ induces a pseudohypoxic state disrupting nuclearmitochondrial communication during aging," Cell, vol. 155, no. 7, pp. 1624-1638, 2013.

[116] S.-J. Lee, A. B. Hwang, and C. Kenyon, "Inhibition of respiration extends C. elegans life span via reactive oxygen species that increase HIF-1 activity," Current Biology, vol. 20, no. 23, pp. 2131-2136, 2010

[117] S.-i. Imai and L. Guarente, "NAD ${ }^{+}$and sirtuins in aging and disease," Trends in Cell Biology, vol. 24, no. 8, pp. 464-471, 2014.

[118] H. Zhang, D. Ryu, Y. Wu et al., "NAD" repletion improves mitochondrial and stem cell function and enhances life span in mice," Science, vol. 352, no. 6292, pp. 1436-1443, 2016.

[119] J. Marín-García and A. T. Akhmedov, "Mitochondrial dynamics and cell death in heart failure," Heart Failure Reviews, vol. 21, no. 2, pp. 123-136, 2016.

[120] Z. Shen, C. Ye, K. McCain, and M. L. Greenberg, "The role of cardiolipin in cardiovascular health," BioMed Research International, vol. 2015, Article ID 891707, 12 pages, 2015.

[121] S.-B. Ong, S. B. Kalkhoran, S. Hernández-Reséndiz, P. Samangouei, S.-G. Ong, and D. J. Hausenloy, "Mitochondrial-shaping proteins in cardiac health and disease-the long and the short of it!," Cardiovascular Drugs and Therapy, vol. 31, no. 1, pp. 87-107, 2017.

[122] D. A. Brown, J. B. Perry, M. E. Allen et al., "Expert consensus document: mitochondrial function as a therapeutic target in heart failure," Nature Reviews Cardiology, vol. 14, no. 4, pp. 238-250, 2017.

[123] C. D. Duve and R. Wattiaux, "Functions of lysosomes," Annual Review of Physiology, vol. 28, pp. 435-492, 1966.

[124] J. D. Rabinowitz and E. White, "Autophagy and metabolism," Science, vol. 330, no. 6009, pp. 1344-1348, 2010.

[125] K. H. Kim and M.-S. Lee, "Autophagy-a key player in cellular and body metabolism," Nature Reviews Endocrinology, vol. 10, no. 6, pp. 322-337, 2014.

[126] O. Lenoir, P.-L. Tharaux, and T. B. Huber, "Autophagy in kidney disease and aging: lessons from rodent models," Kidney International, vol. 90, no. 5, pp. 950-964, 2016.

[127] L. Santambrogio and A. Cuervo, "Chasing the elusive mammalian microautophagy," Autophagy, vol. 7, no. 6, pp. 652654, 2011.

[128] W. Li, Q. Yang, and Z. Mao, "Chaperone-mediated autophagy: machinery, regulation and biological consequences," Cellular and Molecular Life Sciences, vol. 68, no. 5, pp. 749763, 2011.

[129] R. C. Russell, H.-X. Yuan, and K.-L. Guan, "Autophagy regulation by nutrient signaling," Cell Research, vol. 24, no. 1, pp. 42-57, 2014.

[130] J. Lee, S. Giordano, and J. Zhang, "Autophagy, mitochondria and oxidative stress: cross-talk and redox signalling," Biochemical Journal, vol. 441, no. 2, pp. 523-540, 2012.

[131] C. Riehle and E. D. Abel, "Insulin regulation of myocardial autophagy," Circulation Journal, vol. 78, no. 11, pp. 25692576, 2014.

[132] A. Shirakabe, Y. Ikeda, S. Sciarretta, D. K. Zablocki, and J. Sadoshima, "Aging and autophagy in the heart," Circulation Research, vol. 118, no. 10, pp. 1563-1576, 2016.

[133] S. Xu, Y. Cai, and Y. Wei, "mTOR signaling from cellular senescence to organismal aging," Aging and Disease, vol. 5, no. 4, pp. 263-273, 2014.

[134] M. Markaki and N. Tavernarakis, "Metabolic control by target of rapamycin and autophagy during ageing - a minireview," Gerontology, vol. 59, no. 4, pp. 340-348, 2013.

[135] G. Jia, A. R. Aroor, L. A. Martinez-Lemus, and J. R. Sowers, "Overnutrition, mTOR signaling, and cardiovascular diseases," American Journal of Physiology - Regulatory, Integrative and Comparative Physiology, vol. 307, no. 10, pp. R1198-R1206, 2014.

[136] G. R. Y. D. Meyer and W. Martinet, "Autophagy in the cardiovascular system," Biochimica et Biophysica Acta (BBA) Molecular Cell Research, vol. 1793, no. 9, pp. 1485-1495, 2009.

[137] Y. Ikeda, S. Sciarretta, N. Nagarajan et al., "New insights into the role of mitochondrial dynamics and autophagy during oxidative stress and aging in the heart," Oxidative Medicine and Cellular Longevity, vol. 2014, Article ID 210934, 13 pages, 2014.

[138] J. M. Phillip, I. Aifuwa, J. Walston, and D. Wirtz, "The mechanobiology of aging," Annual Review of Biomedical Engineering, vol. 17, pp. 113-141, 2015.

[139] N. E. Seah, C. D. d. Magalhaes Filho, A. P. Petrashen et al., "Autophagy-mediated longevity is modulated by lipoprotein biogenesis," Autophagy, vol. 12, no. 2, pp. 261-272, 2016.

[140] S. M. Solon-Biet, S. J. Mitchell, R. d. Cabo, D. Raubenheimer, D. G. L. Couteur, and S. J. Simpson, "Macronutrients and 
caloric intake in health and longevity," Journal of Endocrinology, vol. 226, no. 1, pp. R17-R28, 2015.

[141] C. D. Wiley and J. Campisi, "From ancient pathways to aging cells-connecting metabolism and cellular senescence," Cell Metabolism, vol. 23, no. 6, pp. 1013-1021, 2016.

[142] X. Sun, T. Komatsu, J. Lim et al., "Nutrient-dependent requirement for SOD1 in lifespan extension by protein restriction in Drosophila melanogaster," Aging Cell, vol. 11, no. 5, pp. 783-793, 2012.

[143] A. Chandrasekaran, M. D. Idelchik, and J. A. Melendez, "Redox control of senescence and age-related disease," Redox Biology, vol. 11, pp. 91-102, 2017.

[144] S. Milman, G. Atzmon, D. M. Huffman et al., "Low insulinlike growth factor-1 level predicts survival in humans with exceptional longevity," Aging Cell, vol. 13, no. 4, pp. 769$771,2014$.

[145] A. E. Webb and A. Brunet, "FOXO transcription factors: key regulators of cellular quality control," Trends in Biochemical Sciences, vol. 39, no. 4, pp. 159-169, 2014.

[146] Y. Wang, Y. Zhou, and D. T. Graves, "FOXO transcription factors: their clinical significance and regulation," BioMed Research International, vol. 2014, Article ID 925350, 13 pages, 2014.

[147] L.-O. Klotz, C. Sánchez-Ramos, I. Prieto-Arroyo, P. Urbánek, H. Steinbrenner, and M. Monsalve, "Redox regulation of FoxO transcription factors," Redox Biology, vol. 6, pp. 5172, 2015.

[148] R. Martins, G. J. Lithgow, and W. Link, "Long live FOXO: unraveling the role of FOXO proteins in aging and longevity," Aging Cell, vol. 15, no. 2, pp. 196-207, 2016.

[149] S. Sciarretta, M. Volpe, and J. Sadoshima, "mTOR signaling in cardiac physiology and disease: Sciarretta et al. mTOR signaling in the cardiovascular system," Circulation Research, vol. 114, no. 3, pp. 549-564, 2014.

[150] T. Nacarelli, A. Azar, and C. Sell, “Aberrant mTOR activation in senescence and aging: a mitochondrial stress response?" Experimental Gerontology, vol. 68, pp. 66-70, 2015.

[151] D.-F. Dai, P. P. Karunadharma, Y. A. Chiao et al., “Altered proteome turnover and remodeling by short-term caloric restriction or rapamycin rejuvenate the aging heart," Aging Cell, vol. 13, no. 3, pp. 529-539, 2014.

[152] K. Burkewitz, H. J. M. Weir, and W. B. Mair, "AMPK as a pro-longevity target," in AMP-Activated Protein Kinase, M. D. Cordero and B. Viollet, Eds., pp. 227-256, Springer International Publishing, Cham, 2016.

[153] D. G. Hardie, "AMPK: positive and negative regulation, and its role in whole-body energy homeostasis," Current Opinion in Cell Biology, vol. 33, pp. 1-7, 2015.

[154] D. G. Hardie, F. A. Ross, and S. A. Hawley, "AMPK: a nutrient and energy sensor that maintains energy homeostasis," Nature Reviews Molecular Cell Biology, vol. 13, no. 4, pp. 251-262, 2012.

[155] A. Martin-Montalvo, E. M. Mercken, S. J. Mitchell et al., "Metformin improves healthspan and lifespan in mice," Nature Communications, vol. 4, article 2192, 2013.

[156] S.-i. Imai and L. Guarente, "It takes two to tango: $\mathrm{NAD}^{+}$and sirtuins in aging/longevity control," Npj Aging and Mechanisms of Disease, vol. 2, article 16017, 2016.

[157] S. Srivastava, "Emerging therapeutic roles for $\mathrm{NAD}^{+}$ metabolism in mitochondrial and age-related disorders,"
Clinical and Translational Medicine, vol. 5, no. 1, pp. 111, 2016.

[158] J. A. Hall, J. E. Dominy, Y. Lee, and P. Puigserver, "The sirtuin family's role in aging and age-associated pathologies," The Journal of Clinical Investigation, vol. 123, no. 3, pp. 973-979, 2013.

[159] M. C. Haigis and D. A. Sinclair, "Mammalian sirtuins: biological insights and disease relevance," Annual Review of Pathology, vol. 5, 2010.

[160] G. Favero, L. Franceschetti, L. F. Rodella, and R. Rezzani, "Sirtuins, aging, and cardiovascular risks," Age, vol. 37, no. 4, p. 65, 2015.

[161] T. Yamamoto, J. Byun, P. Zhai, Y. Ikeda, S. Oka, and J. Sadoshima, "Nicotinamide mononucleotide, an intermediate of $\mathrm{NAD}^{+}$synthesis, protects the heart from ischemia and reperfusion," PloS One, vol. 9, no. 6, article e98972, 2014.

[162] C.-P. Hsu, I. Odewale, R. Alcendor Ralph, and J. Sadoshima, "Sirtl protects the heart from aging and stress," Biological Chemistry, vol. 389, no. 3, pp. 221-231, 2008.

[163] J. Liu, C. Zhang, W. Hu, and Z. Feng, "Tumor suppressor p53 and its mutants in cancer metabolism," Cancer Letters, vol. 356, no. 2, pp. 197-203, 2015.

[164] O. D. K. Maddocks and K. H. Vousden, "Metabolic regulation by p53," Journal of Molecular Medicine, vol. 89, no. 3, pp. 237-245, 2011.

[165] A. Rufini, P. Tucci, I. Celardo, and G. Melino, "Senescence and aging: the critical roles of p53," Oncogene, vol. 32, no. 43, pp. 5129-5143, 2013.

[166] F. Schwartzenberg-Bar-Yoseph, M. Armoni, and E. Karnieli, "The tumor suppressor p53 down-regulates glucose transporters GLUT1 and GLUT4 gene expression," Cancer Research, vol. 64, no. 7, pp. 2627-2633, 2004.

[167] K. H. Vousden and K. M. Ryan, "p53 and metabolism," Nature Reviews Cancer, vol. 9, no. 10, pp. 691-700, 2009.

[168] K. Kawauchi, K. Araki, K. Tobiume, and N. Tanaka, "p53 regulates glucose metabolism through an IKK-NF-[kappa]B pathway and inhibits cell transformation," Nature Cell Biology, vol. 10, no. 5, pp. 611-618, 2008.

[169] P. Jiang, W. Du, and X. Yang, "p53 and regulation of tumor metabolism," Journal of Carcinogenesis, vol. 12, p. 21, 2013.

[170] C.-P. Kung and M. E. Murphy, "The role of the p53 tumor suppressor in metabolism and diabetes," Journal of Endocrinology, vol. 231, no. 2, pp. R61-R75, 2016.

[171] S. Matoba, J.-G. Kang, W. D. Patino et al., "p53 regulates mitochondrial respiration," Science, vol. 312, no. 5780, pp. 1650-1653, 2006.

[172] C. Zhang, M. Lin, R. Wu et al., "Parkin, a p53 target gene, mediates the role of p53 in glucose metabolism and the Warburg effect," Proceedings of the National Academy of Sciences, vol. 108, no. 39, pp. 16259-16264, 2011.

[173] F. Kruiswijk, C. F. Labuschagne, and K. H. Vousden, "p53 in survival, death and metabolic health: a lifeguard with a licence to kill," Nature Reviews Molecular Cell Biology, vol. 16, no. 7, pp. 393-405, 2015.

[174] C. R. Berkers, O. D. K. Maddocks, E. C. Cheung, I. Mor, and K. H. Vousden, "Metabolic regulation by p53 family members," Cell Metabolism, vol. 18, no. 5, pp. 617-633, 2013.

[175] Y. A. Chiao and P. S. Rabinovitch, "The aging heart," Cold Spring Harbor Perspectives in Medicine, vol. 5, no. 9, 2015.

[176] D.-F. Dai, T. Chen, S. C. Johnson, H. Szeto, and P. S. Rabinovitch, "Cardiac aging: from molecular mechanisms 
to significance in human health and disease," Antioxidants \& Redox Signaling, vol. 16, no. 12, pp. 1492-1526, 2012.

[177] F. Paneni, C. Diaz Cañestro, P. Libby, T. F. Lüscher, and G. G. Camici, "The aging cardiovascular system: understanding it at the cellular and clinical levels," Journal of the American College of Cardiology, vol. 69, no. 15, pp. 1952-1967, 2017.

[178] E. G. Lakatta, "So! What's aging? Is cardiovascular aging a disease?" Journal of Molecular and Cellular Cardiology, vol. 83, pp. 1-13, 2015.

[179] G. Santulli and G. Iaccarino, "Adrenergic signaling in heart failure and cardiovascular aging," Maturitas, vol. 93, pp. 65-72, 2016.

[180] K.-T. Kang, "Endothelium-derived relaxing factors of small resistance arteries in hypertension," Toxicological Research, vol. 30, no. 3, pp. 141-148, 2014.

[181] M. A. Ozkor and A. A. Quyyumi, "Endothelium-derived hyperpolarizing factor and vascular function," Cardiology Research and Practice, vol. 2011, Article ID 156146, 12 pages, 2011.

[182] T. P. Ribeiro, A. C. Oliveira, L. G. Mendes-Junior et al., "Cardiovascular effects induced by northeastern Brazilian red wine: role of nitric oxide and redox sensitive pathways," Journal of Functional Foods, vol. 22, pp. 82-92, 2016.

[183] R. F. Furchgott and P. M. Vanhoutte, "Endothelium-derived relaxing and contracting factors," The FASEB Journal, vol. 3, no. 9, pp. 2007-2018, 1989.

[184] Z. Ungvari, G. Kaley, R. d. Cabo, W. E. Sonntag, and A. Csiszar, "Mechanisms of vascular aging: new perspectives," The Journals of Gerontology Series a: Biological Sciences and Medical Sciences, vol. 65A, no. 10, pp. 1028-1041, 2010.

[185] A. Valerio and E. Nisoli, "Nitric oxide, interorganelle communication, and energy flow: a novel route to slow aging," Frontiers in Cell and Developmental Biology, vol. 3, no. 6, 2015.

[186] T. Michel and P. M. Vanhoutte, "Cellular signaling and NO production," Pflugers Archiv : European Journal of Physiology, vol. 459, no. 6, pp. 807-816, 2010.

[187] S. Novella, A. P. Dantas, G. Segarra et al., “Aging-related endothelial dysfunction in the aorta from female senescence-accelerated mice is associated with decreased nitric oxide synthase expression," Experimental Gerontology, vol. 48, no. 11, pp. 1329-1337, 2013.

[188] A. E. Vendrov, K. C. Vendrov, A. Smith et al., "NOX4 $\mathrm{NADPH}$ oxidase-dependent mitochondrial oxidative stress in aging-associated cardiovascular disease," Antioxidants \& Redox Signaling, vol. 23, no. 18, pp. 1389-1409, 2015.

[189] D. R. Seals, R. E. Kaplon, R. A. Gioscia-Ryan, and T. J. LaRocca, "You're only as old as your arteries: translational strategies for preserving vascular endothelial function with aging," Physiology, vol. 29, no. 4, pp. 250-264, 2014.

[190] H.-Y. Lee and B.-H. Oh, "Aging and arterial stiffness," Circulation Journal, vol. 74, no. 11, pp. 2257-2262, 2010.

[191] B. V. Varik, R. Rennenberg, C. Reutelingsperger, A. Kroon, P. de Leeuw, and L. Schurgers, "Mechanisms of arterial remodeling: lessons from genetic diseases," Frontiers in Genetics, vol. 3, no. 290, 2012.

[192] M. Wang and A. M. Shah, "Age-associated pro-inflammatory remodeling and functional phenotype in the heart and large arteries," Journal of Molecular and Cellular Cardiology, vol. 83, pp. 101-111, 2015.
[193] C. Meschiari, O. K. Ero, H. Pan, T. Finkel, and M. L. Lindsey, "The impact of aging on cardiac extracellular matrix," GeroScience, vol. 39, no. 1, pp. 7-18, 2017.

[194] M. AlGhatrif, M. Wang, O. V. Fedorova, A. Y. Bagrov, and E. G. Lakatta, "The pressure of aging," Medical Clinics of North America, vol. 101, no. 1, pp. 81-101, 2017.

[195] G. J. Brewer, "Epigenetic oxidative redox shift (EORS) theory of aging unifies the free radical and insulin signaling theories," Experimental Gerontology, vol. 45, no. 3, pp. 173-179, 2010.

[196] A. Cannatà, G. Marcon, G. Cimmino et al., "Role of circulating factors in cardiac aging," Journal of Thoracic Disease, vol. 9, Supplement 1, pp. S17-S29, 2017.

[197] L. Katsimpardi, N. K. Litterman, P. A. Schein et al., "Vascular and neurogenic rejuvenation of the aging mouse brain by young systemic factors," Science, vol. 344, no. 6184, pp. 630-634, 2014.

[198] P. L. Minciullo, A. Catalano, G. Mandraffino et al., "Inflammaging and anti-inflammaging: the role of cytokines in extreme longevity," Archivum Immunologiae et Therapiae Experimentalis, vol. 64, no. 2, pp. 111-126, 2016.

[199] I. Gregersen, S. Holm, T. B. Dahl, B. Halvorsen, and P. Aukrust, "A focus on inflammation as a major risk factor for atherosclerotic cardiovascular diseases," Expert Review of Cardiovascular Therapy, vol. 14, no. 3, pp. 391-403, 2016.

[200] F. S. Loffredo, M. L. Steinhauser, S. M. Jay et al., "Growth differentiation factor 11 is a circulating factor that reverses age-related cardiac hypertrophy," Cell, vol. 153, no. 4, pp. 828-839, 2013.

[201] Y. Maruyama, "Aging and arterial-cardiac interactions in the elderly," International Journal of Cardiology, vol. 155, no. 1, pp. 14-19, 2012.

[202] A. J. Donato, R. G. Morgan, A. E. Walker, and L. A. Lesniewski, "Cellular and molecular biology of aging endothelial cells," Journal of Molecular and Cellular Cardiology, vol. 89, Part B, pp. 122-135, 2015.

[203] C. Steyers and F. Miller, "Endothelial dysfunction in chronic inflammatory diseases," International Journal of Molecular Sciences, vol. 15, no. 7, article 11324, 2014.

[204] N. Panth, K. R. Paudel, and K. Parajuli, "Reactive oxygen species: a key hallmark of cardiovascular disease," Advances in Medicine, vol. 2016, Article ID 9152732, 12 pages, 2016. 


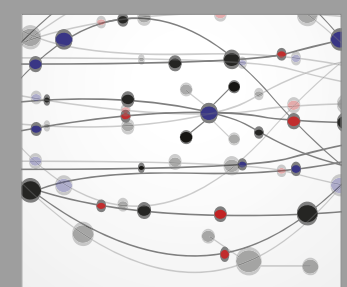

The Scientific World Journal
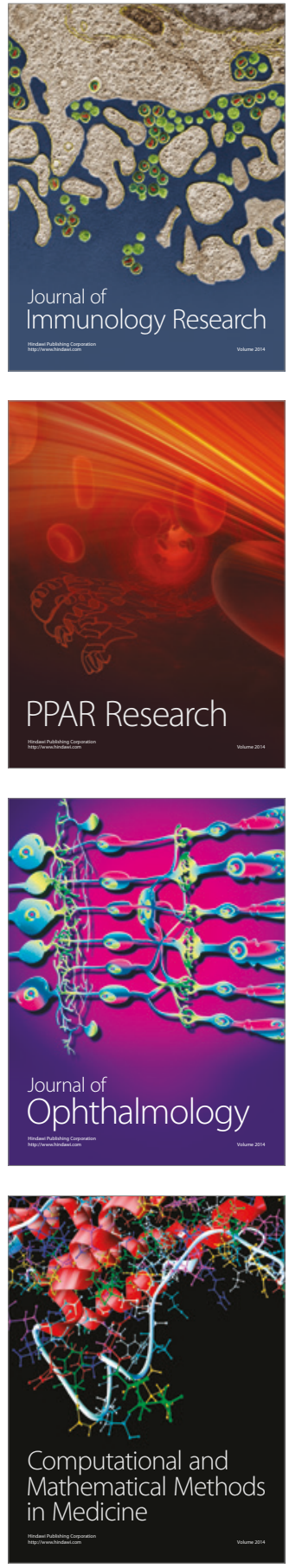

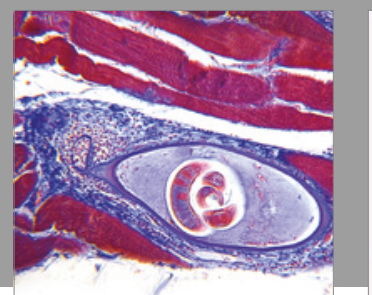

Gastroenterology Research and Practice
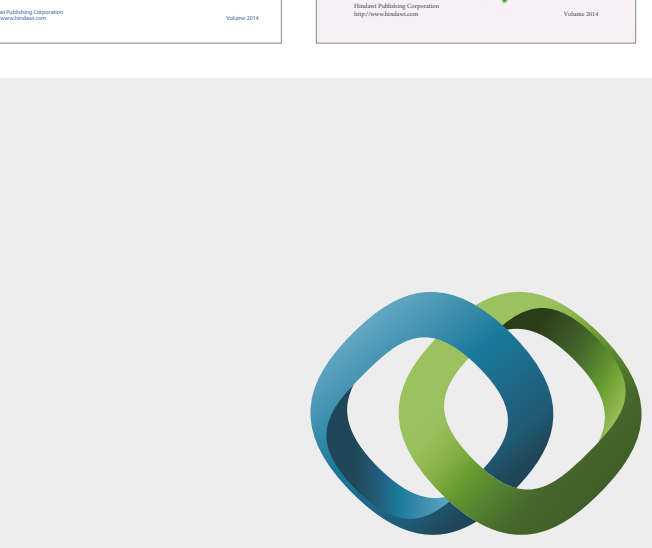

\section{Hindawi}

Submit your manuscripts at

https://www.hindawi.com
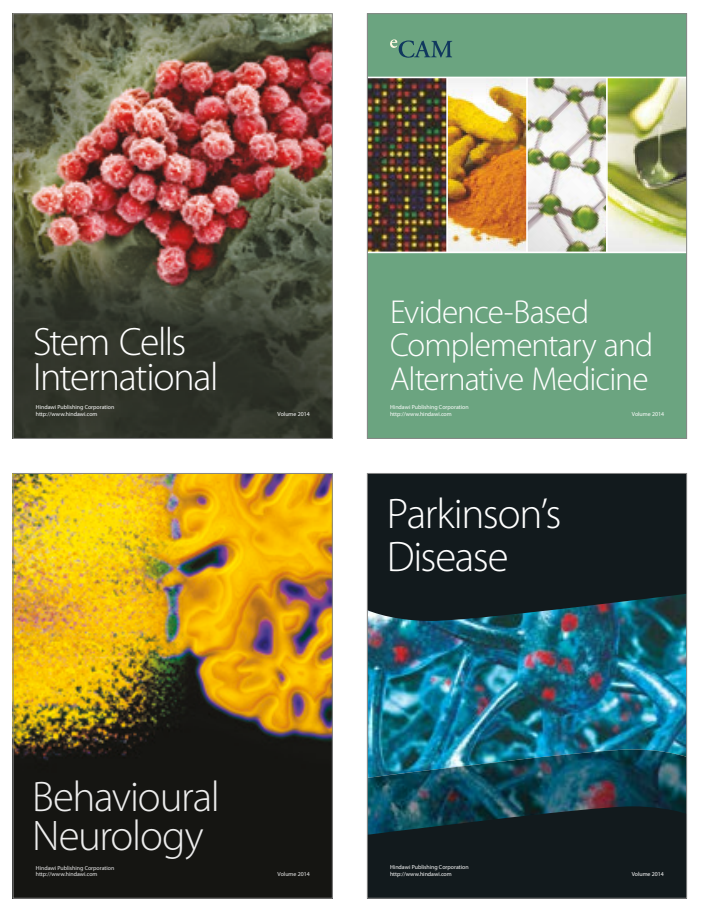
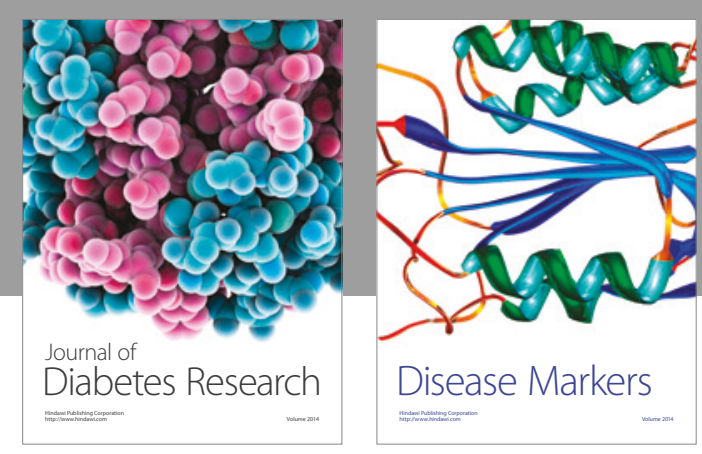

Disease Markers
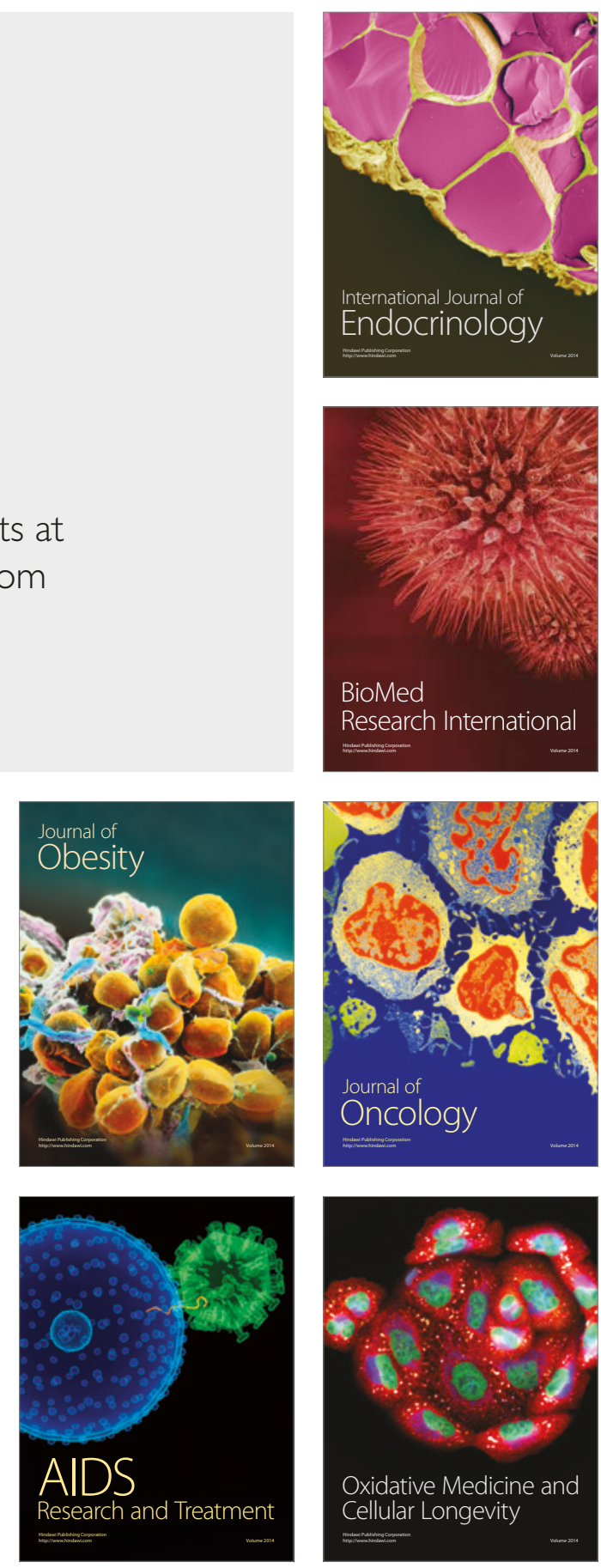